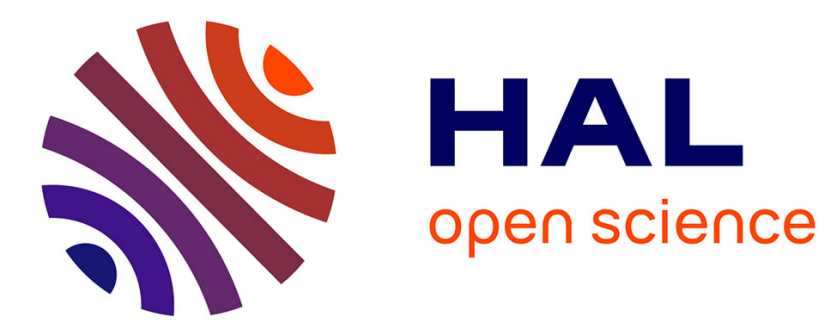

\title{
Currency Union with and without Banking Union
}

Vincent Bignon, Régis Breton, Mariana Rojas Breu

\section{To cite this version:}

Vincent Bignon, Régis Breton, Mariana Rojas Breu. Currency Union with and without Banking Union. 2018. hal-01685893

\section{HAL Id: hal-01685893 https://hal.science/hal-01685893}

Preprint submitted on 16 Jan 2018

HAL is a multi-disciplinary open access archive for the deposit and dissemination of scientific research documents, whether they are published or not. The documents may come from teaching and research institutions in France or abroad, or from public or private research centers.
L'archive ouverte pluridisciplinaire HAL, est destinée au dépôt et à la diffusion de documents scientifiques de niveau recherche, publiés ou non, émanant des établissements d'enseignement et de recherche français ou étrangers, des laboratoires publics ou privés. 


\section{DOCUMENT \\ DE TRAVAIL \\ $N^{\circ} 450$}

\section{CURRENCY UNION WITH OR WITHOUT \\ BANKING UNION}

Vincent Bignon, Régis Breton and Mariana Rojas Breu

October 2013

\section{BANQUE DE FRANCE}

\section{EUROSYSTÈME}


DIRECTION GÉNÉRALE DES ÉTUDES ET DES RELATIONS INTERNATIONALES

\section{CURRENCY UNION WITH OR WITHOUT \\ BANKING UNION}

Vincent Bignon, Régis Breton and Mariana Rojas Breu

October 2013

Les Documents de travail reflètent les idées personnelles de leurs auteurs et n'expriment pas nécessairement la position de la Banque de France. Ce document est disponible sur le site internet de la Banque de France «www.banque-france.fr ».

Working Papers reflect the opinions of the authors and do not necessarily express the views of the Banque de France. This document is available on the Banque de France Website "www.banque-france.fr". 


\title{
Currency Union with and without Banking Union*
}

\author{
Vincent Bignon ${ }^{\dagger}$ \\ Régis Breton ${ }^{\ddagger}$ \\ Mariana Rojas Breu ${ }^{\S}$ \\ Banque de France \\ Banque de France and CNRS \\ Université Paris Dauphine
}

${ }^{*}$ We thank Viral Acharya, Philippe Andrade, Luis Araujo, Aleksander Berentsen, Jean Cartelier, Laurent Clerc, Michael Bordo, Hubert Kempf, Antoine Martin, Julien Matheron, Raoul Minetti, Albrecht Ritschl, Guillaume Rocheteau, Eugene White and seminar participants at SKEMA Business School, Basel Universität, Banque de France, Banco Central de la República Argentina, and participants at the 2013 AFSE conference and 2013 SAET conference for helpful comments. We also thank Jocelyne Tanguy who volunteered her help on the figures. The views expressed herein are those of the authors and should not be interpreted as reflecting those of the Banque of France or the Eurosystem.

${ }^{\dagger}$ Banque de France and EconomiX at Université Paris Nanterre; Address for correspondence: vincent.bignon@banque-france.fr. DGEI - Demfi - Pomone 41-1422; 31 rue Croix des Petits Champs; 75001 Paris France.

${ }^{\ddagger}$ regis.breton@banque-france.fr; DGO - DSF; 31 rue Croix des Petits Champs; 75001 Paris France.

${ }^{\S}$ mariana.rojas-breu@dauphine.fr. LEDa-SDFi; Place du Maréchal de Lattre de Tassigny- 75775 Paris Cedex 16 France. 


\begin{abstract}
Cet article propose un modèle avec monnaie externe, banques et défaut endogène sur les emprunts afin d'analyser l'impact du degré d'imperfection du marché du crédit sur la désirabilité -pour les populations- des unions monétaires. Nous montrons que lorsque ces imperfections entraînent un coût plus élevé pour les banques d'octroyer un crédit sur l'étranger plutôt que dans leur juridiction, le bien-être peut être réduit en régime d'union monétaire. Nous montrons également que la mise en place d'une union bancaire qui supprimerait ces barrières à l'intégration des marchés du crédit restaure le résultat habituel d'optimalité des unions. Les implications empiriques de ces résultats pour l'organisation de l'union bancaire sont discutées.
\end{abstract}

Keywords: banques, union monétaire, crédit, défaut, engagement limité. codes J.E.L.: E42, E50, F3, G21

\begin{abstract}
This paper analyzes a two-country model of currency, banks and endogenous default to study whether impediments to credit market integration across jurisdictions impact the desirability of a currency union. We show that when those impediments induce a higher cost for banks to manage cross-border credit compared to domestic credit, welfare may not be maximal under a regime of currency union. But a banking union that would suppress hurdles to banking integration restores the optimality of that currency arrangement. The empirical and policy implications in terms of banking union are discussed.

Keywords: banks, currency union, credit, default, limited commitment. J.E.L. codes: E42, E50, F3, G21
\end{abstract}




\section{Introduction}

The conditions on the feasibility and optimality of a monetary union are key to the ongoing policy debate in the Euro zone, as policymakers and scholars discuss the features of a banking union to complement the European monetary union. Discussions focus mainly on the creation of a single supervisory mechanism and on the need for a federal fiscal backstop for banking resolution ${ }^{1}$

In this paper we stress another dimension and point to the complementarity between the common currency - high powered money - and the degree of integration across the various bank intermediated credit markets of the zone. We notice that public authorities can easily unify currency conditions but have no direct command over the degree of credit market integration, since loan conditions depend heavily on the behavior of private banks. With the current Eurozone context in mind, we focus our analysis on the cost for banks of one region of the zone to grant credit to residents of another region of the zone. We show that if this cost is high enough, the welfare gains of a common currency and monetary policy may be wiped out.

The logic of this result runs as follows. Consider a situation in which imperfect credit market integration across regions of the zone entails high management costs for loans granted to non-residents, compared to management costs for loans granted to residents. In this environment, the increase in transactions associated with a common currency may worsen default incentives on bank loans. This effect is driven entirely by the distortions in consumption and funding pattern created by limited credit market integration. More specifically, banks charge a higher interest rate for crossborder vis-à-vis domestic purchases. For borrowers, this creates a wedge between the cost of foreign versus domestic consumption, which induces the consumption pattern of agents with no default record to be biased towards domestic goods compared to what would be simply dictated by their preferences. Instead, an agent that would default - something that does not arise on the equilibrium path-would lose access to credit and follow a consumption pattern more aligned with his preferences. Imposing conversion costs between currencies can thus make default less attractive, as this cost can affect more severely defaulters than non-defaulters, whereby relaxing borrowing constraints. By contrast, when cross-border credit does not entail additional costs, there is no home bias induced by differential access to bank credit, and a conversion

\footnotetext{
${ }^{1}$ See for instance Beck (2012), Nieto and White (2013).
} 
cost cannot mitigate default incentives. Thus under perfect credit integration welfare is always higher with a common currency.

Before going further, it is important to be clear about what we mean by imperfect, or limited credit market integration. We define imperfect credit market integration as a situation in which non-residents of a country face more stringent credit conditions (e.g. higher costs) when financing purchases in the foreign country compared to borrowing for domestic consumption. This type of imperfection may come from technological or regulatory hurdles that banks face when granting credit to nonresidents. More importantly in the context of the current debate, those hurdles may originate in a lower ability to seize collateral or revenue across jurisdictions when no automatic procedure for judicial cooperation among jurisdiction is allowed 2 They may reflect a higher cost for banks to access the credit history of non-residents compared to residents $3^{3}$ Impediments to cross-border credit could be exacerbated, or even created by local supervisors or resolution authorities to the extent that they exert 'moral suasion' on banks to favor domestic credit and collateral $4^{4}$ Consequently, one can have perfect integration with respect to the currency dimension - and hence no cost for agents to pay with currency — but imperfect integration of credit markets - and hence a higher cost for cross-border purchases - a configuration that fits the current situation in the Euro zone (see Section 2).

\footnotetext{
${ }^{2}$ Insufficient harmonization of bankruptcy procedures can result in foreign lenders being more exposed to a borrower default than domestic lenders, if the legal procedure relies on implicit and non codified aspects, or if local judges differentiate among lenders on a domestic/foreign basis.

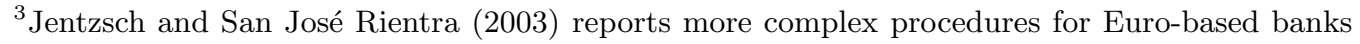
from one country to access cross-border information on customers based in another Euro-area country than for U.S. banks to access cross-state information on a U.S. customer. Jentzsch (2007) further argues that although the situation improved with the adoption of several European directives, "the Commission should ensure enforcement of the existing legislation and should conduct research as to whether there are discriminatory rules in laws at the national level. There are indications that such rules exist in several countries.' Kalemli-Ozcan, Papaioannou, and Peydr (2010) report the uneven pace followed by the various member states to incorporate the provisions of the European directive into the national legislations.

${ }^{4}$ Consistent with this view, Aglietta and Scialom (2003) emphasize the risks created by the disparate views of national prudential entities in a currency union and discuss the induced institutional dilemma. Manna (2011) shows that country-specific bank resolution procedures is an obstacle to credit market integration. Bertay, Demirguç-Kunt, and Huizinga (2011) provide evidence suggesting that country-specific financial safety nets can act as a barrier to cross-border banking. Gros (2012) argues that local supervision encourages the fragmentation of the banking markets in the currency zone.
} 
The result is shown in a symmetric two-country model of fiat money and banks in which the frictions that each help to overcome are explicitly modeled. Currency (fiat money) and bank credit are used in equilibrium by residents of a given country to purchase domestic or foreign goods. In each period, however, agents are subject to individual consumption and production shocks that cannot be efficiently insured by their cash holdings. As in Berentsen, Camera, and Waller (2007), banks provide insurance against those shocks: Agents with no current need for cash (producers) can deposit their currency holdings at their bank rather than keeping them as idle balances, while those with a current need for cash (consumers) can obtain credit from banks to finance additional consumption. By lending out cash received in deposits, banks effectively redistribute the money stock according to agents' current transaction needs. Banks can help finance home or foreign good consumption, albeit at different conditions for residents and non-residents. The various imperfections of credit market integration outlined above share the similarity of generating a cost differential for banks to provide credit for cross-border (foreign) consumption. Because agents cannot commit to repay their debt, banks resort to borrowing constraints and to the exclusion of defaulters from future access to their services to enforce debt repayment. As is standard, the debt enforcement constraint is either irrelevant or binding on equilibrium allocations, depending on the underlying parameters.

To evaluate the gains from a currency union in this environment, we compare two monetary arrangements: a common currency case, and a 'one country-one currency' case with positive conversion costs between the two currencies. The difference between the two cases lies in those conversion costs, and we ask whether the case with strictly positive conversion costs is dominated in terms of welfare by a currency union-which is equivalent to costless conversion. We first show that when the borrowing constraint is not active in equilibrium, a currency union unambiguously dominates the two currency scenario. We then show that this ranking can be reversed in a credit constrained equilibrium, but only if credit integration is limited.

This analysis provides a normative argument for why bank credit integration across regions of a currency zone may be required to (fully) reap the benefit of a currency union, or why a banking union - which should in principle foster credit integration - may be an important complement to a currency union!5 The implica-

\footnotetext{
${ }^{5}$ The U.S. experience during the 19th century exemplifies the distinction between a currency union and a full-fledged monetary union. The dollar currency was created after independence but
} 
tions in terms of design of a banking union are twofold. First, regulators and supervisors should avoid actions that create differences in the costs of managing credit among jurisdictions. Second national legislators must complete the unification of the gathering of information borrowers' creditworthiness; in addition, they should ensure an equal treatment of cross-border claims in national bankruptcy procedures.

The rest of the paper is organized as follows. Section 2 presents some facts on the level of credit market integration in the Euro zone. The environment is laid out in Section 3. The conditions and definition of (symmetric) equilibria are presented in Section 4. Section 5 presents the main results pertaining to the welfare effects of multiples monies and transaction costs. Section 6 discuss the relation of our paper with the literature. Section 7 concludes. Proofs are relegated to the appendix.

\section{The Euro area: one currency, many credit markets}

The currency of the Eurozone countries was unified when they created a unique institution - the European Central Bank (ECB) - to unify the rules governing the issuance of the currency, i.e. cash (banknotes/coins) and balances held on accounts at the ECB. The Maastricht treaty granted residents of those countries equal access to banknotes, independently of the country in which the Euro currency is withdrawn/issued. Hence the introduction of the Euro eliminates exchange rate risk, and it implies that the cost of a banknotes withdrawal is the same in any part of the zone and that credit institutions have an equal access to the Eurosystem operations.

This currency unification coexists with credit markets that are far from being perfectly integrated, despite initiatives aimed at creating a single European market for financial services $\sqrt[6]{6}$ In particular, retail banking markets remain largely unintegrated (Kleimeier and Sander, 2007). While it is hard to measure the extent to which periodic localized banking crisis generated discussions on the redesign of the conditions of currency issuances (Rockoff, 2003, Rousseau, 2013). Although those conditions stabilized somewhat with the National Banking Acts (Weiman and James, 2007), White (1982) argues that differences in regulatory frameworks caused unfulfilled demand for more banking services that "stimulated the public to press for currency and banking reform". It was not before the beginning of the 20th century that the national banking market integrated in terms of payment instruments (James and Weiman, 2010) or national financial integration (Davis, 1965, Sylla, 1969, James, 1976, Choi and Dupont, 2007). Since then it is commonplace to pay in New York with checks drawn on Chicago.

${ }^{\circ}$ For details on ongoing and past European Commission initiatives related to this objective, and in particular the Financial Services Action Plan (FSAP) directives, see http://ec.europa.eu/ internal_market/finances/policy/index_en.htm and ch. 2 in ECB (2012) 
residents of one jurisdiction experience differential access to credit in another jurisdiction or face restrictions in the pledgeability of cross-border collateral, anecdotal evidence abounds. We therefore review the metrics that have been used to provide indirect evidence of financial and credit markets integration in the Euro zone.

Financial market integration in the Euro area increased significantly during the 2000s as a consequence of the introduction of the Euro currency (Hartmann, Maddaloni, and Manganelli, 2003). Those improvements have been unevenly distributed across segments of the financial and banking markets during the last decade. A higher level of integration has been achieved mostly on the equity and bonds markets with a reduction in the home bias in equity and bond holdings (Schoenmaker and Bosch, 2008). Manna (2011) documents a deeper integration in money markets and wholesale banking with banks becoming increasingly interconnected before the subprime crisis, notably through interbank lending. Yet credit markets remain mostly local, with few foreign banks active in multiple jurisdictions, even from other countries of the Eurozone (Sørensen and Gutirrez, 2006, Claessens and van Horen, 2012),7 As a matter of fact in many European countries — notably in core countries - foreign penetration is well below the level that prevails in the U.S. 8

Given available evidence, this limited integration of retail banking markets appears to be a robust feature in the Eurozone. The 2007 ECB report on Financial Integration in Europe writes that "while interbank and capital market-related activities show signs of increasing integration, retail banking markets continue to be less integrated, which is also reflected in the fragmented underlying financial infrastructure" ECB (2007, p.6). This assessment is maintained in subsequent releases of this report: "Financial integration was remarkably fast in money and financial

\footnotetext{
[ Kalemli-Ozcan et al. (2010) exploit differences in the timing of the transposition of European Union financial directives into the state legislation to show that "cross-border banking activities increased significantly among European countries that quickly adopted the financial services directives of the FSAP", suggesting the endogeneity in the adoption of the legal framework to the preference for cross border integration.

${ }^{8}$ As of 2009, the percentage of foreign bank assets among total bank assets was 6 for France, 12 for Germany, 6 for Italy, and 2 for Spain, compared to 18 for the U.S. The respective figures for the percentage of foreign banks was $6,14,10$, and 7, compared to 32 for the U.S. (Claessens and van Horen (2012), tables 1-2). This fact is consistent with the view that retail banking in the U.S. is much more integrated than in the Eurozone. Gropp and Kashyap (2009) present additional evidence in support of this difference in integration levels, using a measure for retail banking integration based on convergence in banks' profitability.
} 
markets; but it was slower and, in fact, never completed in other segments, as described extensively in previous issues of this report. [...]. This judgment has not changed in subsequent years. Cross-border banking through branches or subsidiaries has remained limited, in stark contrast to other forms of banking integration, like interbank deposits or securities holdings, partly as a result of informational asymmetries stemming from supervisory fragmentation" (ECB, 2012, p.90-91).

The Eurozone crisis partly wiped out the gains in the market segments where financial and banking integration was most advanced, notably because of the impairments of the functioning of interbank markets. The de-leveraging of banks balance sheets has been mostly asymmetric, with increase in home bias in several dimensions. Jochem and Volz (2011) find that in each country of the Eurozone "banks have substantially reduced their investment abroad". Acharya and Steffen (2013) use data released by the European Banking Authority to document a marked increased in banks' asset holding home bias. Manna (2011) uses BIS data on the flow of funds between banking systems of both Eurozone and non-Eurozone countries and computes a quarterly index of interbank market integration. The Eurozone number is computed as the average over 10 countries of a measure of home-bias in domestic bank funding vis-à-vis other countries that belong or not to the Eurozone. As shown on graph 1 reproduced from Manna (2011), the Eurozone evolution of home bias in bank funding is U-shaped with a maximum integration in 2007. But in countries of the control group - US, UK, Sweden, Denmark, Switzerland - interbank relationships were not durably impacted by the crisis. This illustrates how the funding of each banking system of the Euro area was re-nationalize during the crisis, which may be related to the variety of resolution mechanisms for distressed banks.

Overall, the evidence points to less than perfect credit integration across countries of the Euro zone, consistent with our emphasis on the distinction between integration in the currency and credit dimensions.

\section{Environment}

Our model is based on Rocheteau and Wright (2005) and Berentsen et al. (2007). Time is discrete and continues forever. There are two identical countries, the home country and the foreign country, each populated by a continuum of infinitely-lived agents of unit mass. There are two perfectly divisible and non-storable goods: a home good, denoted as $q_{h}$, and a foreign good, denoted as $q_{f}$. Agents discount 


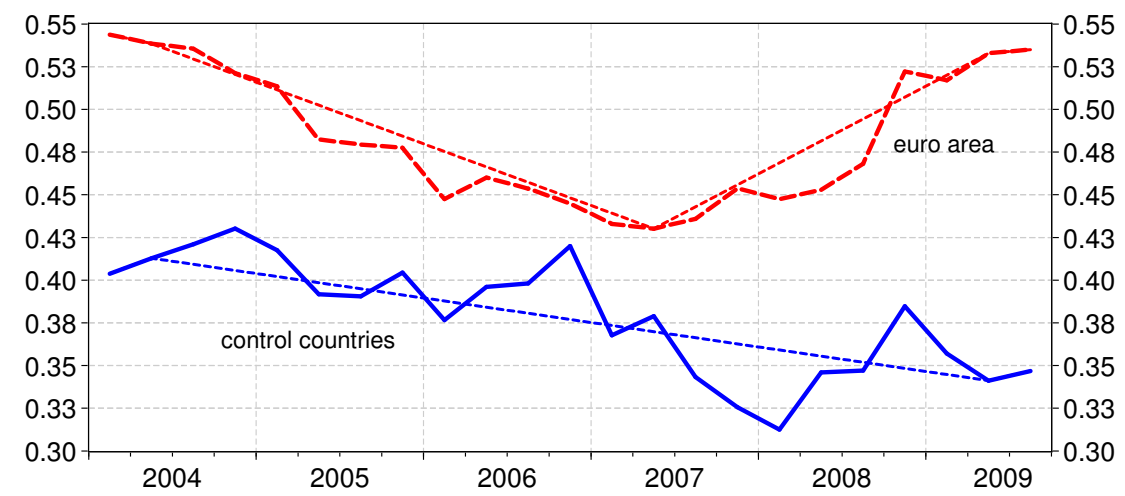

Figure 1: Home bias in banking system, Euro area countries versus control countries (U.S., U.K., Sweden, Denmark, Switzerland). Source: Manna (2011, p. 11)

across periods with factor $\beta$. As in Rocheteau and Wright (2005) a period is divided into two subperiods. In each period, two competitive markets open sequentially in each country. The sequence of trades within a period is depicted in figure 2 . Before the first market opens, agents receive an idiosyncratic shock that determines whether they are producers/sellers for the current period and get no utility from consumption (with probability $(1-b)$ ), or consumers/buyers in which case they want to consume but cannot produce (with probability $b$ ). In the second market, all agents can produce and consume a good denoted as $x$, and utility from consumption (or disutility of working) is linear in the quantity of good.

Buyers' preferences in the first subperiod are

$$
\max \left[u\left(q_{f}\right)+\tilde{\eta} q_{f}, u\left(q_{h}\right)\right]
$$

where $\tilde{\eta}$ is a preference shock which can take values $\eta=0, \eta_{1}$ or $\eta_{2}$ with probabilities $\pi_{0}, \pi_{1}$ and $\pi_{2}$, and $0<\eta_{1}<\eta_{2}$. The function $u$ satisfies the usual Inada conditions. Preferences in (1) are such that in equilibrium buyers will consume the home good in periods in which their idiosyncratic shock $\eta$ is low and consume the foreign good in periods in which $\eta$ is high. In addition, we assume that $\beta<\left[1+b\left(\pi_{1} \eta_{1}+\pi_{2} \eta_{2}\right)\right]^{-1}$. For sellers, producing a quantity $q_{i}($ with $i=(h, f))$ in the first subperiod represents a disutility equal to $c\left(q_{i}\right)=q_{i}$. 
There are two storable, perfectly divisible and intrinsically useless currencies, the home currency and the foreign currency. For simplicity, the quantity of each currency at the beginning of period $t$ is denoted as $M$. The money supply in each country grows at the gross rate $\gamma=M_{+1} / M$ where the subscript +1 indicates the following period. Agents receive monetary lump-sum transfers from the central bank equal to $T=(\gamma-1) M_{-1}$ during the second market in period $t$. Consistently with the current Eurozone situation, we assume that the central bank has no power to tax agents so $\gamma \geq 19$ Currencies can be exchanged before the first market opens. Exchanging currencies represents a disutility $\operatorname{cost} \varepsilon$ proportional to the real amount of money exchanged. Given that the money growth rate is assumed to be the same for the two countries, the case in which the $\operatorname{cost} \varepsilon$ is zero is equivalent to a currency union 10

In order to motivate a role for a medium of exchange, traders are assumed to be anonymous so that sellers require compensation at the same time as they produce. This assumption rules out bilateral credit but not banking credit. Agents can deposit money in banks and borrow to them to finance their purchase. Banking activities take place before the first market opens and after agents have traveled to the foreign country or stayed in their home country. Banks are competitive. Deposits are taken by banks and paid back during the second subperiod with the corresponding interest. A loan is a bilateral contract between an agent and a individual bank. The loan and the interest payment are paid back — if the borrower has an interest to do so during the period of opening of the second market.

Banks have no enforcement power but can store information on agents. More precisely they possess a technology to keep track of financial histories of agents: i.e., they can recognize agents who have defaulted in the past. However, the cost for a bank of identifying a home agent is lower than the cost that the bank incurs to identify a non-resident. For simplicity, we assume that banks incur zero cost in order

\footnotetext{
${ }^{9}$ This restriction implies that the Friedman rule is not a feasible policy, so that it is optimal for agents to insure against idiosyncratic shocks using both (costly) cash holdings and banks. This assumption could be relaxed, for instance by assuming that government can use lump-sum taxes but that agents can evade taxation by not participating in the market - see $\mathrm{Hu}$, Kennan, and Wallace (2009) and Andolfatto (2010).

${ }^{10} \mathrm{We}$ focus on the case in which agents only hold the currency of their country of residence. This is for simplicity and could be justified by assuming that agents face an extra cost (e.g. an accounting cost) when holding a mixed portfolio. The mechanism of the paper does not hinge on this assumption
} 
to recognize residents and they may incur a positive cost in order to recognize a nonresident as described below. Since defaulters are recognized by banks, they can be punished by being excluded from the banking system for the rest of their lifetime; i.e., after defaulting, agents are prevented from borrowing and depositing. The threat of exclusion allows bank credit to be supported in equilibrium. We assume that defaulters are further excluded from monetary transfers.

In addition, agents who stay in the home country can only contact a bank located in the home country (they cannot contact a bank located in the foreign country). Similarly, agents who travel can only contact a bank located in the foreign country. A bank located in the home (foreign) country incurs a cost $c$ per real unit of money lent in order to identify a foreign (home) agent. Since banks are competitive and make zero profit in equilibrium, this cost is transferred to borrowers. For simplicity, $c$ is modeled as a disutility cost incurred by agents at the same time as they take out a loan. When $c=0$, borrowing from a home bank is equivalent to borrowing from a foreign bank, and so banking integration is perfect. If $c>0$, borrowing from a foreign bank is more costly and so there is limited banking integration 11

\section{Symmetric equilibrium}

We focus on stationary equilibria in which end-of-period real money balances are constant, so that

$$
\gamma=M / M_{-1}=\phi_{-1} / \phi
$$

where $\phi$ is the price of money in real terms during the second market. Let $V(m)$ denote the value function of an agent who holds an amount $m$ of money at the beginning of a period. $W(m, \ell)$ is the expected value from entering the second market with $m$ units of money balances and an amount $\ell$ of loans (a negative amount $\ell$ denotes deposits). Since countries are perfectly symmetric, in what follows we only present the optimal choices by agents of the home country.

\footnotetext{
${ }^{11}$ Alternatively, the cost $c$ could be rationalized by a different set of assumptions. Assume that banks can only identify residents (the cost to identify a non-resident is infinite) and that agents can contact a bank located at their country regardless of their location. Then the cost $c$ will be the cost that a home agent who travels incurs in order to contact a home bank from abroad. A third possibility is to assume that banks are able to keep track of the location at which agents purchase goods, which happens if agents pay their purchases using a debit card, as in He, Huang, and Wright (2008). This would allow banks to transfer a cost $c$ to customers whenever they consume abroad.
} 


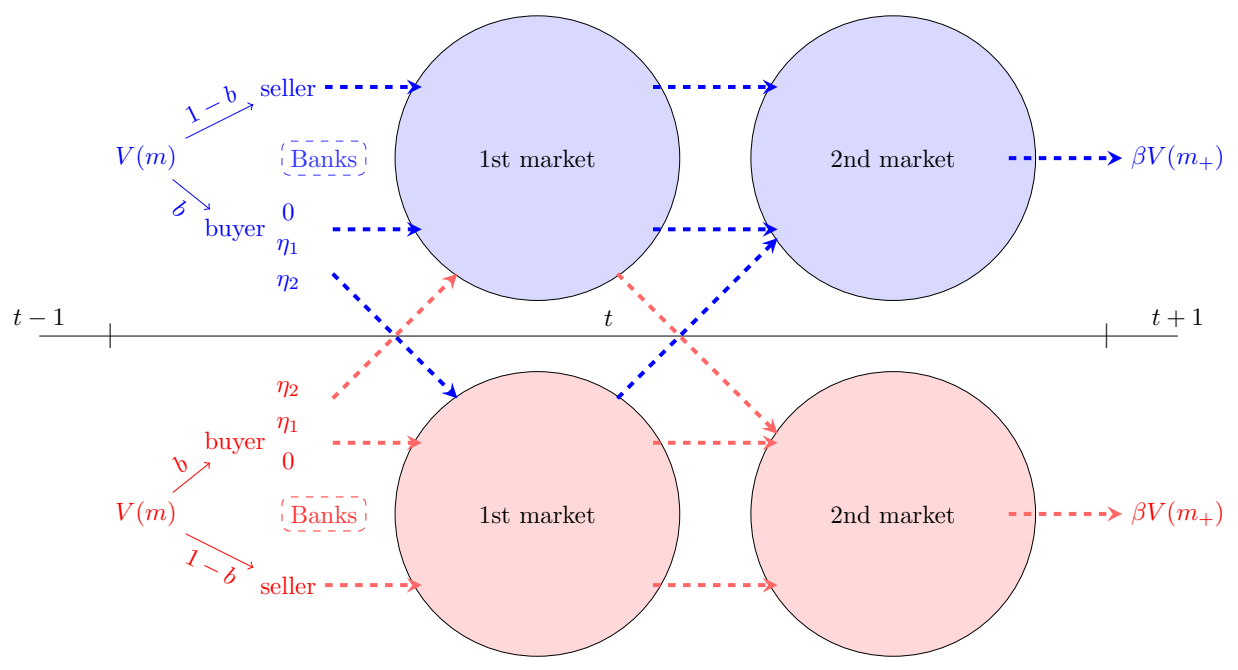

Figure 2: Sequence within a period

\subsection{The second market}

The program for an agent in the second market is

$$
\max _{x, m_{+1}} W(m, \ell)=x+\beta V\left(m_{+1}\right)
$$

s.t. $x+\phi m_{+1}-\phi m+\phi \ell(1+i)-\phi T=0$

where $\phi$ is the price of money in terms of goods in the second market and $T=$ $(\gamma-1) M_{-1}$ are lump-sum transfers from the central bank.

Inserting the budget constraint in the objective function, the above program simplifies to

$$
\max _{m_{+1}}\left[-\phi m_{+1}+\phi m-\phi \ell(1+i)+\phi T+\beta V\left(m_{+1}\right)\right]
$$

The first-order condition on $m_{+1}$ is

$$
\beta V^{\prime}\left(m_{+1}\right)=\phi
$$

The envelope conditions are

$$
\begin{aligned}
W_{m} & =\phi \\
W_{\ell} & =-\phi(1+i)
\end{aligned}
$$




\subsection{The first market}

Sellers

The program for a seller in the first market is

$$
\begin{gathered}
\max _{q_{s}, \ell_{s}}\left[-q_{s}+W\left(m_{-1}+\ell_{s}+p q_{s}, \ell_{s}\right)\right] \\
\text { s.t. }-\ell_{s} \leq m_{-1}
\end{gathered}
$$

where $-\ell_{s}$ are deposits by the seller, $p$ is the price of first-market goods and $q_{s}$ is the quantity sold by the seller. The first-order condition on $q_{s}$ is

$$
W_{m} p=1
$$

Using (4), it becomes

$$
\phi p=1
$$

The first-order condition on $\ell_{s}$ can be written as

$$
\phi i=\mu_{s}
$$

where $\mu_{s}$ is the multiplier associated with the deposit constraint.

\section{Buyers}

Buyers set a threshold $\eta^{*}$ : If $\eta \leq \eta^{*}$, they consume the home good; if $\eta>\eta^{*}$, they consume the foreign good. Denote as $q_{h}$ and $q_{f}^{\eta}$ the consumption quantity of home goods and the consumption quantity of foreign goods, respectively. Denote as $\ell_{h}$ the loan taken by a buyer who consumes the home good. Similarly, let $\ell_{f}^{\eta}$ the loan taken by a buyer with preference shock $\eta=0, \eta_{1}, \eta_{2}$ who consumes the foreign good (notice that, given preferences, $q_{h}$ and hence $\ell_{h}$ do not depend on $\eta$ ). Since banks can distinguish domestic transactions from foreign transactions, they can potentially

set different borrowing limits. Let $\bar{\ell}_{f}$ indicate the borrowing limit for the agent who travels and $\bar{\ell}_{h}$ indicate the borrowing limit for an agent who consumes in the home country.

The program for a buyer with $\eta>\eta^{*}$ is

$$
\begin{gathered}
\max _{q_{f}^{\eta}, \ell_{f}^{\eta}} u\left(q_{f}^{\eta}\right)+(\eta-\varepsilon) q_{f}^{\eta}-c \ell_{f}^{\eta} / p+W\left(m_{-1}+\ell_{f}^{\eta}-p q_{f}^{\eta}, \ell_{f}^{\eta}\right) \\
\text { s.t. } q_{f}^{\eta} \leq\left(m_{-1}+\ell_{f}^{\eta}\right) / p, \quad \ell_{f}^{\eta} \leq \bar{\ell}_{f}
\end{gathered}
$$


This buyer maximizes the utility from consuming $q_{f}^{\eta}$, net from the conversion cost on his good purchases $\varepsilon q_{f}^{\eta}$ and the banking cost $c$ proportional to the real amount of loans taken for consumption of foreign goods. The first constraint is the cash constraint by which the buyer cannot spend more than his initial money holdings plus his borrowing. The second constraint is the borrowing constraint set by banks (to be determined below).

Using (4) and (5), the first-order condition on $q_{f}^{\eta}$ is

$$
u^{\prime}\left(q_{f}^{\eta}\right)+\eta=1+\varepsilon+\mu_{f}^{\eta} / \phi
$$

where $\mu_{f}^{\eta}$ is the multiplier associated with the cash constraint for a buyer with $\eta>\eta^{*}$. The first-order condition on $\ell_{f}^{\eta}$ can be written as

$$
u^{\prime}\left(q_{f}^{\eta}\right)+\eta-\varepsilon-c=1+i+\lambda_{f}^{\eta} / \phi
$$

where $\lambda_{f}^{\eta}$ is the multiplier associated with the borrowing constraint by the buyer with $\eta>\eta^{*}$.

The program for a buyer with $\eta \leq \eta^{*}$ is

$$
\begin{gathered}
\max _{q_{h}, \ell_{h}} u\left(q_{h}\right)+W\left(m_{-1}+\ell_{h}-p q_{h}, \ell_{h}\right) \\
\text { s.t. } q_{h} \leq\left(m_{-1}+\ell_{h}\right) / p, \quad \ell_{h} \leq \bar{\ell}_{h}
\end{gathered}
$$

The first-order condition on $q_{h}$ is

$$
u^{\prime}\left(q_{h}\right)=1+\mu_{h} / \phi
$$

where $\mu_{h}$ is the multiplier associated with the cash constraint by the buyer with $\eta \leq \eta^{*}$.

The first-order condition on $\ell_{h}$ for this buyer can be written as

$$
u^{\prime}\left(q_{h}\right)=1+i+\lambda_{h} / \phi
$$

where $\lambda_{h}$ is the multiplier associated with the borrowing constraint by the buyer with $\eta \leq \eta^{*}$.

\subsection{Market clearing}

Market clearing in the loan market yields

$$
(1-b) \ell_{s}+b \sum_{\eta \leq \eta^{*}} \pi_{\eta} \ell_{h}+b \sum_{\eta>\eta^{*}} \pi_{\eta} \ell_{f}^{\eta}=0
$$


In addition, for sellers it is optimal to deposit their entire money holdings for $\gamma \geq 1$, so $m_{-1}=-\ell_{s}$. Using (11), this equality becomes

$$
m_{-1}=\frac{b}{1-b} \sum_{\eta \leq \eta^{*}} \pi_{\eta} \ell_{h}+\frac{b}{1-b} \sum_{\eta>\eta^{*}} \pi_{\eta} \ell_{f}^{\eta}
$$

Since countries are symmetric, market clearing in the first market for goods yields

$$
b \sum_{\eta \leq \eta^{*}} \pi_{\eta} q_{h}+b \sum_{\eta>\eta^{*}} \pi_{\eta} q_{f}^{\eta}=(1-b) q_{s}
$$

\subsection{Marginal value of money}

The expected utility for an agent who starts a period with $m$ units of money is:

$$
\begin{aligned}
V(m) & =b \sum_{\eta \leq \eta^{*}} \pi_{\eta}\left[u\left(q_{h}\right)+W\left(m+\ell_{h}-q_{h}, \ell_{h}\right)\right] \\
& +b \sum_{\eta>\eta^{*}} \pi_{\eta}\left[u\left(q_{f}^{\eta}\right)+(\eta-\varepsilon) q_{f}^{\eta}-\phi \ell_{f}^{\eta} c+W\left(m+\ell_{f}^{\eta}-q_{f}^{\eta}, \ell_{f}^{\eta}\right)\right] \\
& +(1-b)\left[-q^{s}+W\left(m+\ell_{s}+q_{s}, \ell_{s}\right)\right]
\end{aligned}
$$

Given assumptions on preferences, buyers are cash-constrained for all realizations of $\eta$ if $\gamma \geq 1$. Thus,

$$
\begin{aligned}
\phi\left(m_{-1}+\ell_{h}\right) & =q_{h} \\
\phi\left(m_{-1}+\ell_{f}^{\eta}\right) & =q_{f}^{\eta}
\end{aligned}
$$

Using (4), (6) and (9), the marginal value of money is:

$$
\partial V / \partial m=b \phi \sum_{\eta \leq \eta^{*}} \pi_{\eta} u^{\prime}\left(q_{h}\right)+b \phi \sum_{\eta>\eta^{*}} \pi_{\eta}\left[u^{\prime}\left(q_{f}^{\eta}\right)+\eta-\varepsilon\right]+(1-b) \phi(1+i)
$$

Using (2) and (3), this condition becomes:

$$
\gamma / \beta=b \sum_{\eta \leq \eta^{*}} \pi_{\eta} u^{\prime}\left(q_{h}\right)+b \sum_{\eta>\eta^{*}} \pi_{\eta}\left[u^{\prime}\left(q_{f}^{\eta}\right)+\eta-\varepsilon\right]+(1-b)(1+i)
$$

The left-hand side of this equation represents the marginal cost of acquiring an additional unit of money while the right-hand side represents its marginal benefit: With probability $b$ the agent consumes the home good (for $\eta \leq \eta^{*}$ ) or the foreign good (for $\eta>\eta^{*}$ ), and with probability $(1-b)$ the agent is a seller and earns interests on his deposits. 


\subsection{Borrowing constraint}

Banks do not have enforcement power. Therefore, banks must set a borrowing constraint which ensures voluntary debt repayment: They choose the amount of loans $\ell_{h}$ and $\ell_{f}^{\eta}$ such that the pay-off to an agent who repays his debt is at least equal to the pay-off to a defaulter.

Denote as $\hat{\eta}^{*}$ the threshold value of the preference shock $\eta$ for an agent who has defaulted in the past. In periods in which $\eta \leq \hat{\eta}^{*}$ the defaulter consumes the home good, whereas in periods in which $\eta>\hat{\eta}^{*}$ the defaulter consumes the foreign good. Let $\hat{V}(m)$ indicate the expected utility for a defaulter who starts a period with $m$ units of money. $\hat{V}(m)$ is

$$
\begin{aligned}
\hat{V}(m) & =b \sum_{\eta \leq \hat{\eta}^{*}} \pi_{\eta}\left[u\left(\hat{q}_{h}\right)+\hat{x}_{h}\right]+b \sum_{\eta>\hat{\eta}^{*}}\left[u\left(\hat{q}_{f}^{\eta}\right)+(\eta-\varepsilon) \hat{q}_{f}^{\eta}+\hat{x}^{\eta}\right] \\
& +(1-b)\left(-q^{s}+\hat{x}_{s}\right)
\end{aligned}
$$

where $\hat{x}_{h}, \hat{x}^{\eta}$ and $\hat{x}_{s}$ are net consumption in the second market by the defaulter if he is buyer with $\eta \leq \hat{\eta}^{*}$, if he is a buyer with $\eta>\hat{\eta}^{*}$, and if he is a seller, respectively.

Defaulters do not have access to the banking system. In addition, like nondefaulters, defaulters are cash-constrained for all realizations of $\eta$ for $\gamma \geq 1$. Thus, we can set $\hat{q}_{h}^{\eta}=\hat{q}_{f}^{\eta}=\hat{q}$ for all $\eta$. The amount of money balances that a defaulter holds at the end of each period is then determined by the following optimal condition:

$$
\gamma / \beta=b u^{\prime}(\hat{q})+b \sum_{\eta>\hat{\eta}^{*}} \pi_{\eta}(\eta-\varepsilon)+1-b
$$

Lemma 1 Borrowing limits set by banks satisfy $\bar{\ell}_{h}=\bar{\ell}_{f}^{\eta}$ for all $\eta$. The borrowing constraint set for agents who consume the home good can be written as

$$
\begin{aligned}
& -\phi\left[\ell_{h}(1+i)+m_{-1}\right]+\frac{\beta b}{1-\beta}\left\{\sum_{\eta \leq \eta^{*}} \pi_{\eta}\left[u\left(q_{h}\right)-q_{h}\right]+\sum_{\eta>\eta^{*}} \pi_{\eta}\left[u\left(q_{f}^{\eta}\right)+(\eta-1-\varepsilon) q_{f}^{\eta}-\phi \ell_{f}^{\eta} c\right]\right\} \\
& \geq \frac{\beta b}{1-\beta}\left[u(\hat{q})-\hat{q}+\sum_{\eta>\hat{\eta}^{*}} \pi_{\eta}(\eta-\varepsilon) \hat{q}\right]-\frac{(\gamma-\beta) \hat{q}}{1-\beta}
\end{aligned}
$$

The left-hand side of the borrowing constraint in Lemma 1 represents the pay-off to an agent who does not default. In period $t$, this agent works to pay his loan 
with the corresponding interest and to recover his money holdings. From $t+1$ on, his expected utility is determined by the net utility of consuming the foreign good (minus conversion costs and the banking cost associated with loans for foreign-goods consumption) each time he turns out to be a buyer with $\eta>\eta^{*}$ or the home good each time he turns out to be a buyer with $\eta \leq \eta^{*}$.

The right-hand side of the borrowing constraint represents the pay-off to a defaulter. If an agent defaults, he does not work to repay the loan taken at the beginning of $t$ nor the interest on it. His expected lifetime utility is given by the net utility of consuming $\hat{q}$ as a buyer from $t+1$ on, minus the cost of adjusting money holdings from $t$ on, equal to $(\gamma-\beta) \hat{q} /(1-\beta)$.

\subsection{Travel decision}

The non-defaulter sets the threshold $\eta^{*}$ such that the utility from staying in the home country (consuming the home good) is equal to the utility from traveling to the foreign country (consuming the foreign good). Thus, $\eta^{*}$ is determined by the following condition:

$$
u\left(q_{h}\right)-\phi \ell_{h}(1+i)=u\left(q_{f}^{\eta^{*}}\right)+q_{f}^{\eta^{*}}\left(\eta^{*}-\varepsilon\right)-\phi \ell_{f}^{\eta^{*}}(1+i+c)
$$

given that $m_{-1}+\ell_{h}-p q_{h}=m_{-1}+\ell_{f}^{\eta}-p q_{f}^{\eta}=0$ for all $\eta$. The defaulter sets the threshold $\hat{\eta}^{*}$ as follows

$$
u(\hat{q})=u(\hat{q})+\left(\hat{\eta}^{*}-\varepsilon\right) \hat{q}
$$

given that $\hat{m}_{-1}-p \hat{q}=0$ for all $\eta$. Hence,

$$
\hat{\eta}^{*}=\varepsilon
$$

Definition 2 An equilibrium is a vector of consumption quantities, threshold values of the preference shock, interest rate, price of money, money holdings and loans

$\left\{q_{h}, q_{f}^{\eta}, \hat{q}, \eta^{*}, \hat{\eta}^{*}, i, \phi, m_{-1}, \ell_{h}, \ell_{f}^{\eta}\right\}$ for $\eta \in\left\{0, \eta_{1}, \eta_{2}\right\}$ which satisfy $m_{-1}=M_{-1}$, (8), and (12) - 19). An equilibrium is unconstrained if the borrowing constraint 17) is slack for all values of $\eta$. An equilibrium is fully constrained if the borrowing constraint (17) binds for all values of $\eta$.

Proposition 3 Assume that $\beta>1-b$. Then there is $\tilde{\gamma}$ such that if $\gamma \geq \tilde{\gamma}$, a unique unconstrained equilibrium exists. 
According to Proposition 3 , if the monetary growth rate is sufficiently high, then there is a unique equilibrium and this equilibrium is unconstrained: for all realizations of $\eta$, agents are able to borrow as much as they desire for the prevailing interest rate. This proposition states the usual result in monetary models with limited commitment ${ }^{12}$, Since inflation punishes relatively more defaulters than nondefaulters, there is a level of inflation above which agents who choose to reimburse their loans are able to borrow their desired amount given equilibrium interest rates.

Proposition 4 There is $\hat{\gamma}^{1}, \hat{\gamma}^{2}$ with $\hat{\gamma}^{1}<\hat{\gamma}^{2}<\tilde{\gamma}$ such that if $\gamma \in\left[\hat{\gamma}^{1}, \hat{\gamma}^{2}\right]$ a fully constrained equilibrium exists. $\hat{\gamma}^{1}=1$ if $c=0$ and $\hat{\gamma}^{1}>1$ if $c>0$.

Conversely, if inflation is low enough a constrained equilibrium exists as stated in Proposition 4. In a constrained equilibrium, at the equilibrium interest rate buyers would like to borrow more than banks allow them to. According to Proposition 4. the interval of values of $\gamma$ for which a constrained equilibrium exists depends on $c$. If $c=0$, then $\hat{\gamma}^{1}=1$. However, if $c>0$ no equilibrium with credit exists at $\gamma=1$, so $\hat{\gamma}^{1}>1$. The reason is that if $c>0$ and $\gamma=1$ financing good purchases through the banking system is too costly relatively to doing it by only holding outside money across periods. Since exclusion from the banking system imposes a mild punishment, incentives to default are too high and credit cannot be sustained in equilibrium.

\section{The welfare effect of conversion costs}

In this section, we analyze the effect of making currency exchange costly. As a benchmark, we first assess the effect of implementing conversion costs between the two currencies when agents are not borrowing constrained.

Proposition 5 In an unconstrained equilibrium, imposing positive conversion costs worsens welfare.

Proposition 5 states that imposing positive conversion costs is unambiguously detrimental to welfare if agents are not borrowing constrained. Thus, this proposition replicates a well-known result in monetary theory: Imposing a transaction cost on currency exchange makes agents less willing to trade. Since a conversion

\footnotetext{
${ }^{12}$ See Aiyagari and Williamson (2000), Corbae and Ritter (2004), Berentsen et al. (2007), GomisPorqueras and Sanchez (2013).
} 
cost increases the marginal cost of purchasing goods, buyers choose to increase their marginal utility from consumption and hence consumption decreases.

The following proposition refers to the case in which agents are borrowingconstrained and financial integration among countries is perfect; i.e., $c=0$.

Proposition 6 Let $c=0$. Then in a fully constrained equilibrium imposing positive conversion costs is welfare worsening.

According to Proposition 6, imposing positive conversion costs is welfare worsening when financial markets of the two countries are perfectly integrated so that there are no borrowing cost associated with foreign-goods consumption. The intuition for this result is that non-defaulters who are consumers choose to travel if their preference shock $\eta$ is equal or higher than the conversion cost $\varepsilon ; \eta^{*}=\varepsilon$. As a result, $\eta^{*}=\hat{\eta}^{*}$; i.e., non-defaulters consume the foreign good as often as defaulters. Thus, non-defaulters get punished by conversion costs as much as defaulters do. As when agents are unconstrained, the increase in conversion costs makes agents reduce their consumption and so it is unambigously detrimental to welfare.

Proposition 7 Assume $\pi_{1}>(1 / \beta-1) \pi_{2}$. If $c>\eta_{1} /(1-b)$, then there is $\tilde{\gamma}^{2}$ with $\hat{\gamma}^{1}<\tilde{\gamma}^{2} \leq \hat{\gamma}^{2}$ such that for $\gamma \in\left[\hat{\gamma}^{1}, \tilde{\gamma}^{2}\right]$ in a fully constrained equilibrium imposing positive conversion costs improves welfare.

Proposition 7 states that imposing positive conversion costs is welfare improving if agents are credit-constrained and the banking cost associated with loans for foreign consumption is sufficiently high. If $c$ is high enough, buyers' decision on how often to consume the foreign good relatively to consuming the home good is distorted. If $c>\eta_{1} /(1-b)$, buyers choose to consume the home good instead of the foreign good for $\eta=\eta_{1}$ in order to avoid the cost $c$. By contrast, defaulters do not have access to the banking system, so their decisions are not affected by this cost. Thus, defaulters choose to consume the foreign good whenever it provides them higher utility than the home good; i.e., for $\eta=\eta_{1}$ and $\eta=\eta_{2}$. Since defaulters consume the foreign good more often than non-defaulters, an increase in conversion costs punishes them relatively more than non-defaulters. As a result, conversion costs make default less attractive. In equilibrium a higher provision of credit can be sustained thereby allowing higher consumption. However, since conversion costs still increase the marginal cost of purchasing goods from the buyers' point of view, it must be that 
$\pi_{1}>(1 / \beta-1) \pi_{2}$ so that this negative effect on trade is more than compensated by the effect of conversion costs on incentives to default. Intuitively, this condition states that the probability that all agents incur the conversion costs, $\pi_{2}$, must be relatively low compared to the probability that only defaulters incur the conversion costs, $\pi_{1}$

\subsection{Conversion costs and optimal inflation}

Proposition 7 shows that under appropriate conditions strictly positive conversion costs - and thus multiple currencies - can relax borrowing constraints and improve welfare compared to the benchmark case of a uniform currency. One important insight of the analysis is that less-than-perfect credit integration is a necessary precondition for this welfare increasing effect.

It should be mentioned that these results are obtained taking as given the exogenous inflation rate $(\gamma)$. However, previous studies of economies with credit and limited commitment have shown that inflation can be used to curb default incentives (Aiyagari and Williamson, 2000, Corbae and Ritter, 2004). The mechanism is that a positive inflation rate can hurt more defaulters that non-defaulters since the former are forced to rely on cash transactions to carry their future consumption plans while the latter are partially insulated from inflation through credit arrangements 14 Given this, it is natural to ask whether strictly positive conversion costs are likely to be part of an optimal policy when society can use both instruments ( $\epsilon$ and $\gamma$ ) to mitigate the impact of the debt repayment constraint.

The simulation reported in figure 3 shows that there exist configurations for which positive conversion costs allow higher welfare than what can be attained by a policy of optimal inflation with no conversion costs. ${ }^{15}$ The dotted line corresponds to welfare as a function of the inflation rate when there are no conversion costs.

\footnotetext{
${ }^{13}$ If $c>\eta_{2} /(1-b)$ non-defaulters choose to consume the home good for all realizations of $\eta$ and so this condition is no longer required.

${ }^{14}$ In other words, in this type of environment default is a cash-intensive activity. A positive inflation rate thus acts as a tax that helps to discourage default. In the setup we consider, default is a conversion-intensive activity.

${ }^{15}$ The figure is drawn with the specification $u(q)=\left(q^{\alpha}\right) / \alpha$ and parameters $\beta=0.7, b=0.3, c=$ $0.25, \eta_{1}=0.05, \eta_{2}=0.2, \pi_{1}=0.2, \pi_{2}=0.01$. It has been checked - using Mathematica - that the conditions required for the existence of the fully constrained equilibrium are satisfied for the range of inflation rates that is reported on the horizontal axis.
} 


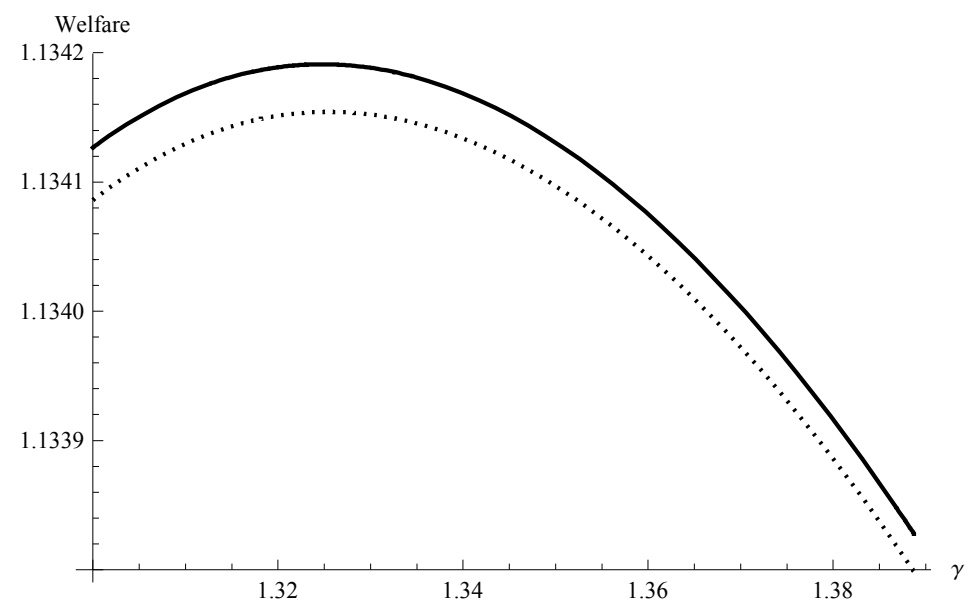

Figure 3: Welfare as a function of inflation with and without conversion costs. (dotted line: $\epsilon=0$; solid line; $\epsilon=0.01$ )

Welfare is maximized at an optimal inflation rate $\gamma^{*}>1$. The solid line corresponds to welfare attained with small, but strictly positive conversion costs. Hence in this example, conversion costs and multiple currencies are optimal, even when choosing inflation optimally 16

\section{Relation to the literature}

Our symmetric framework serves to underscore our contribution to the literature on currency and monetary unions. In particular, we abstract from any source of heterogeneity or asymmetric shocks, so that the type of tradeoffs emphasized in the literature on optimal currency areas do not arise in our setup (Mundell, 1961, De Grauwe, 2007). Our work also differs from studies analyzing public authorities commitment issues, since we consider monetary authorities that are fully committed to a given exogenous inflation rate, and importantly implement the same policy in both countries ${ }^{17}$ For instance, it as been argued that countries that lack internal discipline can commit to monetary stability by joining a currency union with a

\footnotetext{
${ }^{16}$ Of course, even though it is not straightforward from figure 3 the optimal inflation rate also depends on conversion costs.

${ }^{17}$ However, our results do not hinge on exogenous inflation, and the effect of conversion costs that we identify does not disappear when inflation is chosen optimally (see section 5.1).
} 
low-inflation anchor country Alesina and Barro, 2002) 18 On the other hand, some studies have shown that countries may fail to realize the mutual gains to a currency union since by deviating they can use inflation to tax the holding of the foreign holders of domestic currency (Cooper and Kempf, 2003) 19 Another theme emphasized in the vast majority of studies on monetary unions relates to the interaction between monetary and fiscal policies, and how sustainability considerations dictate the type of objectives or constraints that must be imposed on decentralized fiscal authorities. This surge of empirical and theoretical work was aimed at clarifying the terms of the debate on the Maastricht treaty and then on the fiscal and growth pact enacted by the EU. In particular, some argued that sustainability creates a free-rider problem as governments may be tempted to run fiscal deficits financed with others' members resources. Others argued that when default on public debt is not an option, a currency union may be unsustainable because it forbids over-indebted governments to devalue their own currency 20

Our work is also related to a few papers analyzing the potential benefits of multiple monies when there is a commitment issue on the side of private agents rather than public authorities. Building on Ravikumar and Wallace (2001), Kiyotaki and Moore (2003) build a model to show that multiple currencies may be preferred to a common currency when it allows agents to enjoy the benefits of a greater degree of specialization in the production of goods. Kocherlakota and Krueger (1999) provide a setup where multiple monies can be optimal because they allow agents to credibly signal private information concerning the type of goods (home vs. foreign) they prefer. We emphasize a distinct tradeoff, making the point that with imperfect credit integration a common currency can increase the outside option associated with default, and exacerbate agents' incentive to default on their bank loans.

\footnotetext{
${ }^{18}$ See Clerc, Dellas, and Loisel (2011) for a synthesis combining stabilization and credibility considerations.

${ }^{19}$ In a related vein, Liu and Shi $(2010)$ build a search model of money with local congestion on the goods' markets to show that a currency area may not be implemented because with independent monetary policy a country can manipulate its exchange rate to change terms of trades in its favor.

${ }^{20}$ See inter alia Buiter, Roubini, Repullo, and Frankel (1993), Von Hagen and Eichengreen (1996), Cooper and Kempf (2004), Chari and Kehoe (2007), Cooper, Kempf, and Peled (2008), Sargent (2012)
} 


\section{Conclusion}

We have presented a two-country model with money and banks to analyze the conditions for the sustainability of a currency union. We stress the role played by limited credit market integration, that we capture by a difference between domestic and foreign loan management costs. In the model this wedge in management cost triggers a 'bank-induced' home-bias that distorts local consumption towards domestic products and settle the stage for our main result. Because defaulters are excluded from the consumption of banking services, their consumption is more balanced between regions of the zone. This explains why residents of one region may contemplate breaking the currency union by implementing conversion costs. In a situation of banking fragmentation an increase in conversion costs decreases the incentive to default by reducing the value of opportunities of foreign consumption. A banking union that unifies credit conditions across jurisdictions of the zone annihilates this effect.

Two main conclusions are noteworthy. Imperfect banking integration can feedback on the organization of the currency union and even threaten its integrity. This result is new in the theoretical literature analyzing the optimality ,or lack thereof, of currency unions. It may go a long way to explain the lesson taught by students of 19th century U.S. history that localized banking crisis threatened the organization of currency issuance (Rockoff, 2003, Rousseau, 2013). White (1982) argues that during the 1890s differential regulatory treatment between types of banks by public authorities rationed the supply of banking services and stimulated lobbying in favor of a currency and banking reform. The existence of this feedback loop is also coherent with 19th century European evidence on the existence of a correlation between currency integration and banking market integration (Cohen, 1998, Helleiner, 2003).

Another appealing feature of the analysis is that it suggests a novel connection between the degree of credit integration, the extent of local home-bias and the desirability (or, sustainability) of a currency union. This has two broad implications. First — when applicable - moving towards deeper credit integration by reducing the underlying impediments to cross-border credit may be a necessary condition to fully reap the economic gains from a currency union. In that context the main goal to assign to a banking union consists in unifying the credit conditions among regions, in suppressing any regulatory- or politically-induced barriers to integration of lo- 
cal credit markets. Second, if credit integration remains insufficient, integration of the currency itself rather than fostering credit deepening may turn into a source of increased credit rationing on some borrowers, as banks behavior adapt to their borrowers' incentives to default. This potential issue may be more acute in times of crisis. Indeed, if impediments to cross-border credit increase in times of crisis, credit constraints may react more strongly in a currency union.

\section{Appendix}

Proof of Lemma 1. When the settlement stages arrives, the pay-off to a buyer with preference given by $\eta \leq \eta^{*}$ who repays his debt is:

$$
\begin{aligned}
& x_{h}+\frac{\beta b}{1-\beta}\left\{\sum_{\eta \leq \eta^{*}} \pi_{\eta}\left[u\left(q_{h}\right)+x_{h}\right]+\sum_{\eta>\eta^{*}} \pi_{\eta}\left[u\left(q_{f}^{\eta}\right)+(\eta-\varepsilon) q_{f}^{\eta}-\phi \ell_{f}^{\eta} c+x^{\eta}\right]\right\} \\
& -\frac{\beta(1-b)}{1-\beta}\left(q_{s}-x_{s}\right)
\end{aligned}
$$

where $x_{h}, x^{\eta}$ and $x_{s}$ are net consumption by the buyer with $\eta \leq \eta^{*}$, the buyer with $\eta>\eta^{*}$, and the seller, respectively. The pay-off to a defaulter with $\eta \leq \hat{\eta}^{*}$ is

$$
\bar{x}_{h}+\frac{\beta b}{1-\beta}\left\{u(\hat{q})+\sum_{\eta \leq \hat{\eta}^{*}} \pi_{\eta} \hat{x}_{h}+\sum_{\eta>\hat{\eta}^{*}} \pi_{\eta}\left[(\eta-\varepsilon) \hat{q}_{f}^{\eta}+\hat{x}^{\eta}\right]\right\}-\frac{\beta(1-b)}{1-\beta}\left(q_{s}-\hat{x}_{s}\right)
$$

where $\bar{x}_{h}$ is net consumption by the defaulter with $\eta \leq \hat{\eta}^{*}$ in the period in which he defaults and $\hat{x}_{h}, \hat{x}^{\eta}$ and $\hat{x}_{s}$ are net consumption by the defaulter in subsequent periods in case he is a buyer with preference shock $\eta \leq \hat{\eta}^{*}$, a buyer with preference shock $\eta>\hat{\eta}^{*}$, or a seller. In a symmetric equilibrium, $m_{-1}=M_{-1}$. Thus, net consumption quantities $x_{h}, x^{\eta}$ and $x_{s}$ are

$$
\begin{aligned}
& x_{h}=-\phi \ell_{h}(1+i)-\phi m_{+1}+\phi T=-\phi \ell_{h}(1+i)-\phi m_{-1} \\
& x^{\eta}=-\phi \ell^{\eta}(1+i)-\phi m_{+1}+\phi T=-\phi \ell_{f}^{\eta}(1+i)-\phi m_{-1} \\
& x_{s}=-\phi \ell_{s}(1+i)+\phi p q_{s}-\phi m_{+1}+\phi T=-\phi \ell_{s} i+q_{s}
\end{aligned}
$$

Using (11), (12), (13) and (14), we verify the market clearing condition in the second market

$$
b \sum_{\eta \leq \eta^{*}} \pi_{\eta} x_{h}+b \sum_{\eta>\eta^{*}} \pi_{\eta} x^{\eta}+(1-b) x_{s}=0
$$


Net consumption quantities by the defaulter $\bar{x}_{h}, \hat{x}_{h}, \hat{x}^{\eta}$ and $\hat{x}_{s}$ are

$$
\begin{aligned}
& \bar{x}_{h}=\hat{x}_{h}=\hat{x}^{\eta}=-\phi \hat{m}_{+1} \\
& \hat{x}_{s}=\hat{x}^{\eta}+\phi \hat{m}_{-1}+q_{s}
\end{aligned}
$$

with $\phi \hat{m}_{+1}=\gamma \phi \hat{m}_{-1}=\gamma \hat{q}$. Using (20) and (21), the borrowing constraint for agents who consume the home good can be rewritten as in (17). Analogously, the borrowing constraint for agents who consume the foreign good is

$$
\begin{aligned}
& -\phi\left[\ell_{f}^{\eta}(1+i)+m_{-1}\right] \\
& +\frac{\beta b}{1-\beta}\left\{\sum_{\eta \leq \eta^{*}} \pi_{\eta}\left[u\left(q_{h}\right)-q_{h}\right]+\sum_{\eta>\eta^{*}} \pi_{\eta}\left[u\left(q_{f}^{\eta}\right)+(\eta-1-\varepsilon) q_{f}^{\eta}-\phi \ell_{f}^{\eta} c\right]\right\} \\
& \geq \frac{\beta b}{1-\beta}\left[u(\hat{q})-\hat{q}+\sum_{\eta>\hat{\eta}^{*}} \pi_{\eta}(\eta-\varepsilon) \hat{q}\right]-\frac{(\gamma-\beta) \hat{q}}{1-\beta}
\end{aligned}
$$

From 17 and 222 , it follows that $\bar{\ell}_{h}=\bar{\ell}_{f}^{\eta}$ for all $\eta$.

\section{Proof of Proposition 3 .}

Conjecture an unconstrained equilibrium by setting $\lambda_{h}=0$ and $\lambda_{f}^{\eta}=0$ for all $\eta>\eta^{*}$. From (15), it follows

$$
\gamma / \beta-b \sum_{\eta>\eta^{*}} \pi_{\eta} c=1+i
$$

Thus, from $\sqrt{8}$ and $\sqrt{10} q_{h}$ and $q_{f}^{\eta}$ are immediatetly pinned down for a given value of $\gamma$. In addition, from (11), (12) and (14),

$$
\phi \ell_{h}=(1-b) q_{h}-b \sum_{\eta>\eta^{*}} \pi_{\eta}\left(q_{f}^{\eta}-q_{h}\right)
$$

and $q_{h}-\phi \ell_{h}=q_{f}^{\eta}-\phi \ell_{f}^{\eta}$ for all $\eta$. By the mean value theorem, $u\left(q_{h}\right)-u(\hat{q})-q_{h}+\hat{q}>$ $\left[u^{\prime}\left(q_{h}\right)-1\right]\left(q_{h}-\hat{q}\right)$. Similarly, $u\left(q_{f}^{\eta}\right)+(\eta-\varepsilon-1) q_{f}^{\eta}-u(\hat{q})-(\eta-\varepsilon-1) \hat{q}>$ $\left[u^{\prime}\left(q_{f}^{\eta}\right)+\eta-\varepsilon-1\right]\left(q_{f}^{\eta}-\hat{q}\right)$. Hence, a sufficient condition for the borrowing con- 
straint (17) to be non-binding is

$$
\begin{aligned}
& -\phi \ell_{h} i-q_{h}-\frac{\beta b}{1-\beta} \sum_{\eta>\eta^{*}} \pi_{\eta} \phi \ell_{f}^{\eta} c \\
& +\frac{\beta b}{1-\beta}\left\{\sum_{\eta \leq \eta^{*}} \pi_{\eta}\left[u^{\prime}\left(q_{h}\right)-1\right]\left(q_{h}-\hat{q}\right)+\sum_{\eta>\eta^{*}} \pi_{\eta}\left[u^{\prime}\left(q_{f}^{\eta}\right)+\eta-\varepsilon-1\right]\left(q_{f}^{\eta}-\hat{q}\right)\right\} \\
& \geq-\frac{(\gamma-\beta) \hat{q}}{1-\beta}
\end{aligned}
$$

Since $u^{\prime}\left(q_{h}\right)=u^{\prime}\left(q_{f}^{\eta}\right)+\eta-\varepsilon-c=1+i$ and $q_{h}-\phi \ell_{h}=q_{f}^{\eta}-\phi \ell_{f}^{\eta}$, this condition can be rewritten as

$$
\begin{aligned}
& -\phi \ell_{h} i-q_{h}+\frac{\beta b c}{1-\beta} \sum_{\eta>\eta^{*}} \pi_{\eta}\left(q_{h}-\phi \ell_{h}\right) \\
& +\frac{\beta b i}{1-\beta}\left(\sum_{\eta \leq \eta^{*}} \pi_{\eta} q_{h}+\sum_{\eta>\eta^{*}} \pi_{\eta} q_{f}^{\eta}\right) \geq-\frac{(\gamma-\beta) \hat{q}}{1-\beta}+\frac{\beta b}{1-\beta}\left(i+\sum_{\eta>\eta^{*}} \pi_{\eta} c\right) \hat{q}
\end{aligned}
$$

Using (23) and (24), it becomes

$$
\begin{aligned}
& -(1-b) q_{h} i+b \sum_{\eta>\eta^{*}} \pi_{\eta}\left(q_{f}^{\eta}-q_{h}\right) i-q_{h}+\frac{\beta b c}{1-\beta} \sum_{\eta>\eta^{*}} b \pi_{\eta}\left(q_{h}+\sum_{\eta>\eta^{*}} \pi_{\eta}\left(q_{f}^{\eta}-q_{h}\right)\right) \\
& +\frac{\beta b i}{1-\beta}\left(\sum_{\eta \leq \eta^{*}} \pi_{\eta} q_{h}+\sum_{\eta>\eta^{*}} \pi_{\eta} q_{f}^{\eta}\right) \geq-\beta i \frac{1-b}{1-\beta} \hat{q}
\end{aligned}
$$

Since the right-hand side in the above inequality is negative and $q_{h}<q_{f}^{\eta}$, a sufficient condition for this inequality to hold is

$$
-(1-b) q_{h} i-q_{h}+\frac{\beta b c}{1-\beta} \sum_{\eta>\eta^{*}} b \pi_{\eta} q_{h}+\frac{\beta b i}{1-\beta} q_{h} \geq 0
$$

Simplifying,

$$
\beta b c \sum_{\eta>\eta^{*}} b \pi_{\eta}+(\beta+b-1) i \geq 1-\beta
$$

Given (23), it follows that this inequality always holds if $\beta>1-b$ and

$$
\gamma \geq \frac{\beta b}{\beta+b-1}\left[1-(1-b)(1-\beta) c \sum_{\eta>\eta^{*}} \pi_{\eta}\right]
$$


If the borrowing constraint does not bind for any agent, (23) pins down $i$ and hence $q_{h}$ and $q_{f}^{\eta}$ for all $\eta$ so the equilibrium is unique.

\section{Proof of Proposition 4 .}

Case $\varepsilon+(1-b) c<\eta_{1}$.

Consider the borrowing constraint in 17 and conjecture a fully constrained equilibrium. Since in this equilibrium all buyers are credit-constrained, let $q$ denote $q=q_{h}=q_{f}^{1}=q_{f}^{2}$. From (18), the threshold $\eta^{*}$ is determined by

$$
\eta^{*}=\varepsilon+(1-b) c
$$

Since $\eta^{*}<\eta_{1}$, 15 and (16) can be rewritten as follows:

$$
\gamma / \beta-1=b\left[u^{\prime}(q)+\pi_{1}\left(\eta_{1}-\varepsilon\right)+\pi_{2}\left(\eta_{2}-\varepsilon\right)-1\right]+(1-b) i
$$

whereas $(16)$ is

$$
\gamma / \beta-1=b\left[u^{\prime}(\hat{q})+\pi_{1}\left(\eta_{1}-\varepsilon\right)+\pi_{2}\left(\eta_{2}-\varepsilon\right)-1\right]
$$

In addition, rewrite (17) as follows:

$$
\begin{aligned}
& -i(1-b) q-q \\
& +\frac{\beta b}{1-\beta}\left\{u(q)-q+\pi_{1}\left(\eta_{1}-\varepsilon\right) q+\pi_{2}\left(\eta_{2}-\varepsilon\right) q-\left(\pi_{1}+\pi_{2}\right)(1-b) c q\right\} \\
& =\frac{\beta b}{1-\beta}\left\{u(\hat{q})+\left[-1+\pi_{1}\left(\eta_{1}-\varepsilon\right)+\pi_{2}\left(\eta_{2}-\varepsilon\right)\right] \hat{q}\right\}-\frac{(\gamma-\beta) \hat{q}}{1-\beta}
\end{aligned}
$$

Differentiate (27) with respect to $\gamma$ to get

$$
\begin{aligned}
& -\frac{\partial i}{\partial \gamma}(1-b) q-[i(1-b)+1] \frac{\partial q}{\partial \gamma} \\
& +\frac{\beta b}{1-\beta}\left\{u^{\prime}(q)-1+\pi_{1}\left(\eta_{1}-\varepsilon\right)+\pi_{2}\left(\eta_{2}-\varepsilon\right)-\left(\pi_{1}+\pi_{2}\right)(1-b) c\right\} \frac{\partial q}{\partial \gamma} \\
& =\frac{\beta b}{1-\beta}\left\{u^{\prime}(\hat{q})-1+\pi_{1}\left(\eta_{1}-\varepsilon\right)+\pi_{2}\left(\eta_{2}-\varepsilon\right)\right\} \frac{\partial \hat{q}}{\partial \gamma}-\frac{\gamma-\beta}{1-\beta} \frac{\partial \hat{q}}{\partial \gamma}-\frac{\hat{q}}{1-\beta}
\end{aligned}
$$

Since $1 / \beta=b u^{\prime \prime}(q)(\partial q / \partial \gamma)+(1-b)(\partial i / \partial \gamma)$, we use 25$)$ and 26$)$ to get

$$
\frac{\partial q}{\partial \gamma}=\frac{(1-\beta) q / \beta-\hat{q}}{(1-\beta) b u^{\prime \prime}(q) q+\gamma-1-i(1-b)-\beta b\left(\pi_{1}+\pi_{2}\right)(1-b) c}
$$

and

$$
\beta(1-b) \frac{\partial i}{\partial \gamma}=\frac{\gamma-1-i(1-b)-\beta b\left(\pi_{1}+\pi_{2}\right)(1-b) c+\beta b u^{\prime \prime}(q) \hat{q}}{\gamma-1-i(1-b)-\beta b\left(\pi_{1}+\pi_{2}\right)(1-b) c+(1-\beta) b u^{\prime \prime}(q) q}
$$


For a constrained equilibrium to exist, it must be that $i \geq 0$, which implies $q \geq \hat{q}$ given (25) and (26). Denote as $\hat{\gamma}^{1}$ the value of $\gamma$ such that $\hat{q}=q$ in a fully constrained equilibrium. From (25) and (26), $i=0$ at $\gamma=\hat{\gamma}^{1}$. Thus, from (27) $\hat{\gamma}^{1}$ satisfies $\hat{\gamma}^{1}=1+\beta b\left(\pi_{1}+\pi_{2}\right)(1-b) c$.

From (27), we get

$$
\begin{aligned}
& -i(1-b)-1 \\
& =\frac{\beta b}{1-\beta} \frac{u(\hat{q})+\left[-1+\pi_{1}\left(\eta_{1}-\varepsilon\right)+\pi_{2}\left(\eta_{2}-\varepsilon\right)\right] \hat{q}}{q}-\frac{(\gamma-\beta) \hat{q} / q}{1-\beta} \\
& -\frac{\beta b}{1-\beta} \frac{u(q)-q+\pi_{1}\left(\eta_{1}-\varepsilon\right) q+\pi_{2}\left(\eta_{2}-\varepsilon\right) q-\left(\pi_{1}+\pi_{2}\right)(1-b) c q}{q}
\end{aligned}
$$

Therefore,

$$
\begin{aligned}
& \gamma-i(1-b)-1-\beta b\left(\pi_{1}+\pi_{2}\right)(1-b) c \\
& =\gamma-\beta b\left(\pi_{1}+\pi_{2}\right)(1-b) c+\frac{\beta b}{1-\beta} \frac{u(\hat{q})+\left[-1+\pi_{1}\left(\eta_{1}-\varepsilon\right)+\pi_{2}\left(\eta_{2}-\varepsilon\right)\right] \hat{q}}{q}-\frac{(\gamma-\beta) \hat{q} / q}{1-\beta} \\
& -\frac{\beta b}{1-\beta} \frac{u(q)-q+\pi_{1}\left(\eta_{1}-\varepsilon\right) q+\pi_{2}\left(\eta_{2}-\varepsilon\right) q-\left(\pi_{1}+\pi_{2}\right)(1-b) c q}{q}
\end{aligned}
$$

By the mean value theorem, $u(q)-u(\hat{q})-q+\hat{q}>\left[u^{\prime}(q)-1\right](q-\hat{q})$ for $q>\hat{q}$. Therefore, for $q>\hat{q}$ (or $i>0$ ) we verify from 29 that

$$
\gamma-i(1-b)-1-\beta b\left(\pi_{1}+\pi_{2}\right)(1-b) c<-\beta(1-b) i \frac{\hat{q}}{q}
$$

so $\gamma-i(1-b)-1-\beta b\left(\pi_{1}+\pi_{2}\right)(1-b) c$ is unambiguously negative for $i>0$ and given $\hat{\gamma}^{1}$ it is equal to zero for $i=0$. Therefore, from $\sqrt{28}$ it follows that $\partial i / \partial \gamma>0$ for $i>0$ provided that the borrowing constraint binds. At $\gamma=\hat{\gamma}^{1}, i=0$ by definition of $\hat{\gamma}^{1}$. Therefore, from $(28) \partial i / \partial \gamma>0$ at $\gamma=\hat{\gamma}^{1}$ and so $i>0$ at $\gamma$ slightly higher than $\hat{\gamma}^{1}$. In turn, this implies that $\gamma-i(1-b)-1-\beta b\left(\pi_{1}+\pi_{2}\right)(1-b) c$ is negative for $\gamma$ slightly higher than $\hat{\gamma}^{1}$ and hence it follows from 28 that $\partial i / \partial \gamma>0$ at $\gamma$ slightly higher than $\hat{\gamma}^{1}$. Therefore, $i>0$ for $\gamma$ even higher. Hence there is an interval $\left[\hat{\gamma}^{1}, \hat{\gamma}^{2}\right]$ such that if $\gamma \in\left[\hat{\gamma}^{1}, \hat{\gamma}^{2}\right]$ then $i \geq 0$ and so a constrained equilibrium exists.

Case $\eta_{1}-\varepsilon<(1-b) c<\eta_{2}-\varepsilon$.

Consider the borrowing constraint in (17) and conjecture a fully constrained equilibrium. Since in this equilibrium all buyers are credit-constrained, let $q$ denote 
$q=q_{h}=q_{f}^{1}=q_{f}^{2}$. From $\left(18\right.$, the threshold $\eta^{*}$ is determined by

$$
\eta^{*}=\varepsilon+(1-b) c
$$

Since $\eta_{1}<\eta^{*}<\eta_{2}$, 15) can be rewritten as:

$$
\gamma / \beta=b u^{\prime}(q)+b \pi_{2}\left(\eta_{2}-\varepsilon\right)+(1-b)(1+i)
$$

Money holdings by defaulters are determined by

$$
\gamma / \beta-1=b\left[u^{\prime}(\hat{q})+\pi_{1}\left(\eta_{1}-\varepsilon\right)+\pi_{2}\left(\eta_{2}-\varepsilon\right)-1\right]
$$

In addition, rewrite (17) as follows:

$$
\begin{aligned}
& -i(1-b) q-q+\frac{\beta b}{1-\beta}\left\{u(q)-q+\pi_{2}\left[\eta_{2}-\varepsilon-(1-b) c\right] q\right\} \\
& =\frac{\beta b}{1-\beta}\left\{u(\hat{q})+\left[-1+\pi_{1}\left(\eta_{1}-\varepsilon\right)+\pi_{2}\left(\eta_{2}-\varepsilon\right)\right] \hat{q}\right\}-\frac{(\gamma-\beta) \hat{q}}{1-\beta}
\end{aligned}
$$

Differentiate (32) with respect to $\gamma$ to get

$$
\begin{aligned}
& -\frac{\partial i}{\partial \gamma}(1-b) q-[i(1-b)+1] \frac{\partial q}{\partial \gamma}+\frac{\beta b}{1-\beta}\left\{u^{\prime}(q)-1+\pi_{2}\left[\eta_{2}-\varepsilon-(1-b) c\right]\right\} \frac{\partial q}{\partial \gamma} \\
& =\frac{\beta b}{1-\beta}\left\{u^{\prime}(\hat{q})-1+\pi_{1}\left(\eta_{1}-\varepsilon\right)+\pi_{2}\left(\eta_{2}-\varepsilon\right)\right\} \frac{\partial \hat{q}}{\partial \gamma}-\frac{\gamma-\beta}{1-\beta} \frac{\partial \hat{q}}{\partial \gamma}-\frac{\hat{q}}{1-\beta}
\end{aligned}
$$

Since $1 / \beta=b u^{\prime \prime}(q)(\partial q / \partial \gamma)+(1-b)(\partial i / \partial \gamma)$, use 30 and $(31)$ to get

$$
\frac{\partial q}{\partial \gamma}=\frac{(1-\beta) q / \beta-\hat{q}}{(1-\beta) b q u^{\prime \prime}(q)+\gamma-1-(1-b) i-\beta b \pi_{2}(1-b) c}
$$

and

$$
(1-b) \beta \frac{\partial i}{\partial \gamma}=\frac{\beta b u^{\prime \prime}(q) \hat{q}+\gamma-1-(1-b) i-\beta b \pi_{2}(1-b) c}{(1-\beta) b u^{\prime \prime}(q) q+\gamma-1-(1-b) i-\beta b \pi_{2}(1-b) c}
$$

For a constrained equilibrium to exist, it must be that $i \geq 0$. As in the case $\varepsilon+(1-b) c<\eta_{1}$, let $\hat{\gamma}^{1}$ denote the value of $\gamma$ such that $\hat{q}=q$ in a fully constrained equilibrium. From 30 and (31), at $\gamma=\hat{\gamma}^{1}(1-b) i=b \pi_{1}\left(\eta_{1}-\varepsilon\right)$ so that $i>0$. Thus, from (32), in this case $\hat{\gamma}^{1}$ satisfies $\hat{\gamma}^{1}=1+\beta b \pi_{2}(1-b) c+b \pi_{1}\left(\eta_{1}-\varepsilon\right)$.

From 32 , we get

$$
\begin{aligned}
& -i(1-b)-1 \\
& =\frac{\beta b}{1-\beta} \frac{u(\hat{q})+\left[-1+\pi_{1}\left(\eta_{1}-\varepsilon\right)+\pi_{2}\left(\eta_{2}-\varepsilon\right)\right] \hat{q}}{q}-\frac{(\gamma-\beta) \hat{q} / q}{1-\beta} \\
& -\frac{\beta b}{1-\beta} \frac{u(q)-q+\pi_{2}\left[\eta_{2}-\varepsilon-(1-b) c\right] q}{q}
\end{aligned}
$$


Therefore,

$$
\begin{aligned}
& \gamma-i(1-b)-1-\beta b \pi_{2}(1-b) c \\
& =\gamma-\beta b \pi_{2}(1-b) c+\frac{\beta b}{1-\beta} \frac{u(\hat{q})+\left[-1+\pi_{1}\left(\eta_{1}-\varepsilon\right)+\pi_{2}\left(\eta_{2}-\varepsilon\right)\right] \hat{q}}{q}-\frac{(\gamma-\beta) \hat{q} / q}{1-\beta} \\
& -\frac{\beta b}{1-\beta} \frac{u(q)-q+\pi_{2}\left[\eta_{2}-\varepsilon-(1-b) c\right] q}{q}
\end{aligned}
$$

By the mean value theorem, $u(q)-u(\hat{q})-q+\hat{q}>\left[u^{\prime}(q)-1\right](q-\hat{q})$ for $q>\hat{q}$. Therefore, for $q>\hat{q}$ (or $i>b \pi_{2}\left(\eta_{2}-\varepsilon\right) /(1-b)$ ) we verify from (34) that

$$
\gamma-i(1-b)-1-\beta b \pi_{2}(1-b) c<\beta\left[b \pi_{1}\left(\eta_{1}-\varepsilon\right)-(1-b) i\right] \hat{q} / q
$$

The right-hand side in (35) is negative for $q>\hat{q}$ (or $b \pi_{1}\left(\eta_{1}-\varepsilon\right)<(1-b) i$ ) and it is equal to zero at $\gamma=\hat{\gamma}^{1}$; i.e., for $q=\hat{q}$ (or $(1-b) i=b \pi_{1}\left(\eta_{1}-\varepsilon\right)$ ). Therefore $\gamma-i(1-b)-1-\beta b \pi_{2}(1-b) c$ is unambiguously negative for $q>\hat{q}$ and it is equal to zero at $\gamma=\hat{\gamma}^{1}$. Hence from (33) $\partial i / \partial \gamma>0$ at $\gamma=\hat{\gamma}^{1}$ so $i>b \pi_{1}\left(\eta_{1}-\varepsilon\right) /(1-b)>0$ at $\gamma$ slightly higher than $\hat{\gamma}^{1}$. In turn, this implies that $\gamma-i(1-b)-1-\beta b \pi_{2}(1-b) c$ is negative for $\gamma$ slightly higher than $\hat{\gamma}^{1}$ and hence it follows from 33 that $\partial i / \partial \gamma>0$ at $\gamma$ slightly higher than $\hat{\gamma}^{1}$. Therefore, $i>b \pi_{1}\left(\eta_{1}-\varepsilon\right) /(1-b)>0$ for $\gamma$ even higher. Hence there is an interval $\left[\hat{\gamma}^{1}, \hat{\gamma}^{2}\right]$ such that if $\gamma \in\left[\hat{\gamma}^{1}, \hat{\gamma}^{2}\right]$ then $i \geq 0$ and so a constrained equilibrium exists. Notice from 32 that given assumptions on $c$ at $\gamma=1$ there is no equilibrium with credit.

Case $\eta_{2}-\varepsilon<(1-b) c$.

Consider the borrowing constraint in (17) and conjecture a fully constrained equilibrium. Since in this equilibrium all buyers are credit-constrained, let $q$ denote $q=q_{h}=q_{f}^{1}=q_{f}^{2}$. From (18), the threshold $\eta^{*}$ is determined by

$$
\eta^{*}=\varepsilon+(1-b) c
$$

Since $\eta^{*}>\eta_{2}, 15$ can be rewritten as:

$$
\gamma / \beta=b u^{\prime}(q)+(1-b)(1+i)
$$

Money holdings by defaulters are determined by

$$
\gamma / \beta-1=b\left[u^{\prime}(\hat{q})+\pi_{1}\left(\eta_{1}-\varepsilon\right)+\pi_{2}\left(\eta_{2}-\varepsilon\right)-1\right]
$$


In addition, rewrite (17) as follows:

$$
\begin{aligned}
& -i(1-b) q-q+\frac{\beta b}{1-\beta}[u(q)-q] \\
& =\frac{\beta b}{1-\beta}\left\{u(\hat{q})+\left[-1+\pi_{1}\left(\eta_{1}-\varepsilon\right)+\pi_{2}\left(\eta_{2}-\varepsilon\right)\right] \hat{q}\right\}-\frac{(\gamma-\beta) \hat{q}}{1-\beta}
\end{aligned}
$$

Differentiate (38) with respect to $\gamma$ to get

$$
\begin{aligned}
& -\frac{\partial i}{\partial \gamma}(1-b) q-[i(1-b)+1] \frac{\partial q}{\partial \gamma}+\frac{\beta b}{1-\beta}\left[u^{\prime}(q)-1\right] \frac{\partial q}{\partial \gamma} \\
& =\frac{\beta b}{1-\beta}\left\{u^{\prime}(\hat{q})-1+\pi_{1}\left(\eta_{1}-\varepsilon\right)+\pi_{2}\left(\eta_{2}-\varepsilon\right)\right\} \frac{\partial \hat{q}}{\partial \gamma}-\frac{\gamma-\beta}{1-\beta} \frac{\partial \hat{q}}{\partial \gamma}-\frac{\hat{q}}{1-\beta}
\end{aligned}
$$

Since $1 / \beta=b u^{\prime \prime}(q)(\partial q / \partial \gamma)+(1-b)(\partial i / \partial \gamma)$, use (36) and (37) to get

$$
\frac{\partial q}{\partial \gamma}=\frac{(1-\beta) q / \beta-\hat{q}}{(1-\beta) b q u^{\prime \prime}(q)+\gamma-1-(1-b) i}
$$

and

$$
(1-b) \beta \frac{\partial i}{\partial \gamma}=\frac{\beta b u^{\prime \prime}(q) \hat{q}+\gamma-1-(1-b) i}{(1-\beta) b u^{\prime \prime}(q) q+\gamma-1-(1-b) i}
$$

For a constrained equilibrium to exist, it must be that $i \geq 0$. As in previous cases, let $\hat{\gamma}^{1}$ denote the value of $\gamma$ such that $\hat{q}=q$ in a fully constrained equilibrium. From (36) and (37), at $\gamma=\hat{\gamma}^{1}(1-b) i=b \pi_{1}\left(\eta_{1}-\varepsilon\right)+b \pi_{2}\left(\eta_{2}-\varepsilon\right)$ so that $i>0$. From (38), in this case $\hat{\gamma}^{1}$ satisfies $\hat{\gamma}^{1}=1+b \pi_{2}\left(\eta_{2}-\varepsilon\right)+b \pi_{1}\left(\eta_{1}-\varepsilon\right)$.

From $(38)$, we get

$$
\begin{aligned}
& -i(1-b)-1 \\
& =\frac{\beta b}{1-\beta} \frac{u(\hat{q})+\left[-1+\pi_{1}\left(\eta_{1}-\varepsilon\right)+\pi_{2}\left(\eta_{2}-\varepsilon\right)\right] \hat{q}}{q}-\frac{(\gamma-\beta) \hat{q} / q}{1-\beta} \\
& -\frac{\beta b}{1-\beta} \frac{u(q)-q}{q}
\end{aligned}
$$

Therefore,

$$
\begin{aligned}
& \gamma-i(1-b)-1 \\
& =\gamma+\frac{\beta b}{1-\beta} \frac{u(\hat{q})+\left[-1+\pi_{1}\left(\eta_{1}-\varepsilon\right)+\pi_{2}\left(\eta_{2}-\varepsilon\right)\right] \hat{q}}{q}-\frac{(\gamma-\beta) \hat{q} / q}{1-\beta} \\
& -\frac{\beta b}{1-\beta} \frac{u(q)-q}{q}
\end{aligned}
$$


By the mean value theorem, $u(q)-u(\hat{q})-q+\hat{q}>\left[u^{\prime}(q)-1\right](q-\hat{q})$ for $q>\hat{q}$. Therefore, for $q>\hat{q}$ (or $\left.i>b\left[\pi_{1}\left(\eta_{1}-\varepsilon\right)+\pi_{2}\left(\eta_{2}-\varepsilon\right)\right] /(1-b)\right)$ we verify from 40 that

$$
\gamma-1-(1-b) i<\beta\left[-(1-b) i+b \pi_{1}\left(\eta_{1}-\varepsilon\right)+b \pi_{2}\left(\eta_{2}-\varepsilon\right)\right] \frac{\hat{q}}{q}
$$

The right-hand side in (41) is negative for $q>\hat{q}$ (or $b \pi_{1}\left(\eta_{1}-\varepsilon\right)+b \pi_{2}\left(\eta_{2}-\varepsilon\right)<$ $(1-b) i$ ) and it is equal to zero at $\gamma=\hat{\gamma}^{1}$; i.e., for $q=\hat{q}$ (or $(1-b) i=b \pi_{1}\left(\eta_{1}-\varepsilon\right)+$ $\left.b \pi_{2}\left(\eta_{2}-\varepsilon\right)\right)$. Therefore $\gamma-1-i(1-b)$ is unambiguously negative for $q>\hat{q}$ and it is equal to zero at $\gamma=\hat{\gamma}^{1}$. Hence from 39 (39) $\partial \gamma>0$ at $\gamma=\hat{\gamma}^{1}$ so $i>$ $b\left[\pi_{1}\left(\eta_{1}-\varepsilon\right)+\pi_{2}\left(\eta_{2}-\varepsilon\right)\right] /(1-b)>0$ at $\gamma$ slightly higher than $\hat{\gamma}^{1}$. In turn, this implies that $\gamma-1-i(1-b)$ is negative for $\gamma$ slightly higher than $\hat{\gamma}^{1}$ and hence it follows from (39) that $\partial i / \partial \gamma>0$ at $\gamma$ slightly higher than $\hat{\gamma}^{1}$. Therefore, $i>$ $b\left[\pi_{1}\left(\eta_{1}-\varepsilon\right)+\pi_{2}\left(\eta_{2}-\varepsilon\right)\right] /(1-b)>0$ for $\gamma$ even higher. Hence there is an interval $\left[\hat{\gamma}^{1}, \hat{\gamma}^{2}\right]$ such that if $\gamma \in\left[\hat{\gamma}^{1}, \hat{\gamma}^{2}\right]$ then $i \geq 0$ and so a constrained equilibrium exists. Notice from (38) that given assumptions on $c$ at $\gamma=1$ there is no equilibrium with credit.

Proof of Proposition 5. In an unconstrained equilibrium all agents borrow as much as they desire. Since $\lambda_{h}=\lambda_{f}^{\eta}=0,8$ and 10 become

$$
\begin{array}{r}
u^{\prime}\left(q_{h}\right)=1+i \\
u^{\prime}\left(q_{f}^{\eta}\right)+\eta-\varepsilon-c=1+i
\end{array}
$$

Therefore 15 becomes

$$
\gamma / \beta=u^{\prime}\left(q_{f}^{\eta}\right)+\eta-\varepsilon-\left(b \sum_{\eta \leq \eta^{*}} \pi_{\eta}+1-b\right) c
$$

Hence

$$
\partial q_{f}^{\eta} / \partial \varepsilon=1 / u^{\prime \prime}\left(q_{f}^{\eta}\right)
$$

so that $q_{f}^{\eta}$ is decreasing in $\varepsilon$. From $\sqrt{42}$ and $\left.\sqrt{43}\right), \partial q_{h} / \partial \varepsilon=0$. Therefore, an increase in $\varepsilon$ decreases agents' expected lifetime utility.

Proof of Proposition 6. Let $c=0$ and consider a fully constrained equilibrium in which $\lambda_{h}, \lambda_{f}^{\eta}>0$ and the borrowing constraint (17) holds with equality. Thus, we can set $\phi \ell_{h}=\phi \ell_{f}^{\eta}=\phi \ell$ and $q_{h}=q_{f}^{\eta}=q$ for all $\eta$. From 11, 12, and 14 
$\phi \ell=(1-b) q$ and $\phi m_{-1}=b q$. From 18$], \eta^{*}=\varepsilon$ if $c=0$. Rewrite the borrowing constraint (17) by setting $c=0$ and $\eta_{2}>\eta_{1}>\varepsilon$ :

$$
\begin{aligned}
& -[1+(1-b) i] q+\frac{\beta b}{1-\beta}\left\{u(q)-q+\left[\pi_{1}\left(\eta_{1}-\varepsilon\right)+\pi_{2}\left(\eta_{2}-\varepsilon\right)\right] q\right\} \\
& =\frac{\beta b}{1-\beta}\left\{u(\hat{q})-\hat{q}+\left[\pi_{1}\left(\eta_{1}-\varepsilon\right)+\pi_{2}\left(\eta_{2}-\varepsilon\right)\right] \hat{q}\right\}-\frac{(\gamma-\beta) \hat{q}}{1-\beta}
\end{aligned}
$$

Differentiate with respect to $\varepsilon$ to get

$$
\begin{aligned}
& -[1+(1-b) i] \frac{\partial q}{\partial \varepsilon}-(1-b) \frac{\partial i}{\partial \varepsilon} q-\frac{\beta b\left(\pi_{1}+\pi_{2}\right)}{1-\beta} q \\
& +\frac{\beta b}{1-\beta}\left[u^{\prime}(q)-1+\pi_{1}\left(\eta_{1}-\varepsilon\right)+\pi_{2}\left(\eta_{2}-\varepsilon\right)\right] \frac{\partial q}{\partial \varepsilon} \\
& =\frac{\beta b}{1-\beta}\left[u^{\prime}(\hat{q})-1+\pi_{1}\left(\eta_{1}-\varepsilon\right)+\pi_{2}\left(\eta_{2}-\varepsilon\right)\right] \frac{\partial \hat{q}}{\partial \varepsilon}-\frac{\beta b\left(\pi_{1}+\pi_{2}\right)}{1-\beta} \hat{q}-\frac{\gamma-\beta}{1-\beta} \frac{\partial \hat{q}}{\partial \varepsilon}
\end{aligned}
$$

Rewrite (15) and (16) as follows

$$
\begin{aligned}
& \gamma / \beta=b u^{\prime}(q)-b+b\left[\pi_{1}\left(\eta_{1}-\varepsilon\right)+\pi_{2}\left(\eta_{2}-\varepsilon\right)\right]+1+(1-b) i \\
& \gamma / \beta=b u^{\prime}(\hat{q})-b+b\left[\pi_{1}\left(\eta_{1}-\varepsilon\right)+\pi_{2}\left(\eta_{2}-\varepsilon\right)\right]+1
\end{aligned}
$$

Differentiating (46) with respect to $\varepsilon$ yields $(1-b)(\partial i / \partial \varepsilon)=-b u^{\prime \prime}(q)(\partial q / \partial \varepsilon)+$ $b\left(\pi_{1}+\pi_{2}\right)$. Rewrite (45) using 46) and 47) to get

$$
\frac{\partial q}{\partial \varepsilon}=\frac{b\left(\pi_{1}+\pi_{2}\right)[(1-\beta) q+\beta(q-\hat{q})]}{\gamma-1-(1-b) i+(1-\beta) b q u^{\prime \prime}(q)}
$$

From (46) and (47), $q=\hat{q}$ when $i=0$ and $q>\hat{q}$ when $i>0$. From Proposition 4. when $c=0$ the value of $\gamma$ such that $i=0$ and $q=\hat{q}, \hat{\gamma}^{1}$, is $\hat{\gamma}^{1}=1$ and $q \geq \hat{q}$ for $\gamma \in\left[\hat{\gamma}^{1}, \hat{\gamma}^{2}\right]$. Therefore, the numerator at the right-hand side in 48 is positive for $\gamma \in\left[1, \hat{\gamma}^{2}\right]$. A sufficient condition for the denominator to be negative is that $\gamma-1-(1-b) i \leq 0$. From (44), when the borrowing constraint binds $\gamma-1-(1-b) i$ is

$$
\begin{aligned}
& \gamma-1-(1-b) i \\
& =-\beta(1-b) i \\
& +\beta b[u(\hat{q})-u(q)]-\left\{\gamma-\beta+\beta b\left[\pi_{1}\left(\eta_{1}-\varepsilon\right)+\pi_{2}\left(\eta_{2}-\varepsilon\right)-1\right]\right\}(\hat{q}-q)
\end{aligned}
$$

Since $q \geq \hat{q}$ and $i \geq 0$ for $\gamma \in\left[1, \hat{\gamma}^{2}\right]$, it follows that $\gamma-1-i(1-b) \leq 0$ for $\gamma \in\left[1, \hat{\gamma}^{2}\right]$. Thus, the denominator at right-hand side in 48 is negative. It follows that in a fully constrained equilibrium $\partial q / \partial \varepsilon<0$ for $\gamma \in\left[1, \hat{\gamma}^{2}\right]$. 
Proof of Proposition 7. Consider a fully constrained equilibrium in which $\lambda_{h}, \lambda_{f}^{\eta}>$ 0 and the borrowing constraint $(17)$ holds with equality. It follows that $q_{h}=q_{f}^{\eta}=q$ and $\phi \ell_{h}=\phi \ell_{f}^{\eta}=\phi \ell$ for all $\eta$. Thus, from $\sqrt{11}, \sqrt{12}$ and $14 \phi \phi \ell=(1-b) q$ and $\phi m_{-1}=b q$. From 18$), \eta^{*}=\varepsilon+(1-b) c$.

Case $\varepsilon<\eta_{1}<\varepsilon+(1-b) c<\eta_{2}$.

Rewrite the borrowing constraint (17) as follows:

$$
\begin{aligned}
& -[(1-b) i+1] q+\frac{\beta b}{1-\beta}\left\{u(q)-q+\pi_{2}\left[\eta_{2}-\varepsilon-(1-b) c\right] q\right\} \\
& =\frac{\beta b}{1-\beta}\left\{u(\hat{q})-\hat{q}+\left[\pi_{1}\left(\eta_{1}-\varepsilon\right)+\pi_{2}\left(\eta_{2}-\varepsilon\right)\right] \hat{q}\right\}-\frac{(\gamma-\beta) \hat{q}}{1-\beta}
\end{aligned}
$$

where 19 has been used. Differentiate with respect to $\varepsilon$ to get

$$
\begin{aligned}
& -(1-b) \frac{\partial i}{\partial \varepsilon} q-\frac{\beta b}{1-\beta}\left[\pi_{2} q-\left(\pi_{1}+\pi_{2}\right) \hat{q}\right] \\
& -[1+(1-b) i] \frac{\partial q}{\partial \varepsilon}+\frac{\beta b}{1-\beta}\left\{u^{\prime}(q)-1+\pi_{2}\left[\eta_{2}-\varepsilon-(1-b) c\right]\right\} \frac{\partial q}{\partial \varepsilon} \\
& =\frac{\beta b}{1-\beta}\left\{u^{\prime}(\hat{q})-1+\left[\pi_{1}\left(\eta_{1}-\varepsilon\right)+\pi_{2}\left(\eta_{2}-\varepsilon\right)\right]\right\} \frac{\partial \hat{q}}{\partial \varepsilon}-\frac{\gamma-\beta}{1-\beta} \frac{\partial \hat{q}}{\partial \varepsilon}
\end{aligned}
$$

Rewrite 15 and (16) as follows

$$
\begin{aligned}
& \gamma / \beta=b\left[u^{\prime}(q)-1+\pi_{2}\left(\eta_{2}-\varepsilon\right)\right]+1+(1-b) i \\
& \gamma / \beta=b\left[u^{\prime}(\hat{q})-1+\pi_{1}\left(\eta_{1}-\varepsilon\right)+\pi_{2}\left(\eta_{2}-\varepsilon\right)\right]+1
\end{aligned}
$$

Differentiating (51) with respect to $\varepsilon$ yields $(1-b)(\partial i / \partial \varepsilon)=-b u^{\prime \prime}(q)(\partial q / \partial \varepsilon)+$ $b \pi_{2}$. Using (51) and (52), (50) becomes

$$
\frac{\partial q}{\partial \varepsilon}=\frac{b \pi_{2} q+\beta b\left[\pi_{2} q-\left(\pi_{1}+\pi_{2}\right) \hat{q}\right] /(1-\beta)}{b u^{\prime \prime}(q) q+\left[\gamma-1-(1-b) i-\beta b(1-b) \pi_{2} c\right] /(1-\beta)}
$$

A sufficient condition for the denominator in (53) to be negative is that $\gamma-$ $1-(1-b) i-\beta b(1-b) \pi_{2} c \leq 0$. From (49), when the borrowing constraint binds $\gamma-1-(1-b) i-\beta b(1-b) \pi_{2} c$ is

$$
\begin{aligned}
& \gamma-1-(1-b) i-\beta b(1-b) \pi_{2} c \\
& =-\beta(1-b) i+\frac{\beta b[u(\hat{q})-u(q)]-\left\{\gamma-\beta+\beta b\left[\pi_{2}\left(\eta_{2}-\varepsilon\right)-1\right]\right\}(\hat{q}-q)}{q} \\
& +\beta b \pi_{1}\left(\eta_{1}-\varepsilon\right) \hat{q} / q
\end{aligned}
$$


From Proof of Proposition 4, when $\eta_{1}<\varepsilon+(1-b) c$ the value of $\gamma$ such that $q=\hat{q}, \hat{\gamma}^{1}$, is $\hat{\gamma}^{1}=1+\beta b \pi_{2}(1-b) c+b \pi_{1}\left(\eta_{1}-\varepsilon\right)$. In addition, $q \geq \hat{q}$ and $i \geq$ $b \pi_{2}\left(\eta_{2}-\varepsilon\right) /(1-b)$ for $\gamma \in\left[\hat{\gamma}^{1}, \hat{\gamma}^{2}\right]$. Therefore, given $(\mathbf{5 4}) \gamma-1-(1-b) i-$ $\beta b(1-b) \pi_{2} c \leq 0$ for $\gamma \in\left[\hat{\gamma}^{1}, \hat{\gamma}^{2}\right]$. Thus, the denominator at the right-hand side of (53) is negative.

For $\gamma=\hat{\gamma}^{1}, q=\hat{q}$ and so the numerator at the right-hand side of $(53)$ is negative since $\pi_{2}-\beta \pi_{1} /(1-\beta)<0$. Therefore, $\partial q / \partial \varepsilon>0$ at $\gamma=\hat{\gamma}^{1}$. However, since $q$ is increasing in $\varepsilon$ as long as the numerator at the right-hand side of (53) is positive and $\hat{q}$ is decreasing in $\varepsilon$ given (52), the numerator at the right-hand side of (53) is increasing in $\varepsilon$. Define $\hat{\gamma}^{2 \prime}$ the value of $\gamma$ such that for $\{q, \hat{q}, i\}$ which satisfy (49), (51) and (52) the numerator at the right-hand side of (53) is zero. In addition, let $\tilde{\gamma}^{2}=\min \left(\hat{\gamma}^{2}, \hat{\gamma}^{2 \prime}\right)$. Then $\partial q / \partial \varepsilon>0$ for $\gamma \in\left[\hat{\gamma}^{1}, \tilde{\gamma}^{2}\right]$ and so in a fully constrained equilibrium conversion costs increase agents' lifetime utility.

Case $\varepsilon<\eta_{1}<\eta_{2}<\varepsilon+(1-b) c$.

Assume that $\eta_{2} \leq \bar{\eta}$ with

$$
b \bar{\eta}=\frac{u(q)-u(b q)}{q}-(1-b) u^{\prime}(q)
$$

(55) obtains from (18) if it is assumed that agents do not resort to banks for foreigngood consumption in a fully constrained equilibrium. Therefore, assuming $\eta_{2} \leq \bar{\eta}$ allows to dismiss the case in which agents would choose to consume the foreign good without resorting to banks in a fully constrained equilibrium. Rewrite the borrowing constraint (17) as follows:

$$
\begin{aligned}
& -[(1-b) i+1] q+\frac{\beta b}{1-\beta}[u(q)-q] \\
& =\frac{\beta b}{1-\beta}\left\{u(\hat{q})-\hat{q}+\left[\pi_{1}\left(\eta_{1}-\varepsilon\right)+\pi_{2}\left(\eta_{2}-\varepsilon\right)\right] \hat{q}\right\}-\frac{(\gamma-\beta) \hat{q}}{1-\beta}
\end{aligned}
$$

where $(19)$ has been used. Differentiate with respect to $\varepsilon$ to get

$$
\begin{aligned}
& -(1-b) \frac{\partial i}{\partial \varepsilon} q+\frac{\beta b}{1-\beta}\left(\pi_{1}+\pi_{2}\right) \hat{q} \\
& -[1+(1-b) i] \frac{\partial q}{\partial \varepsilon}+\frac{\beta b}{1-\beta}\left[u^{\prime}(q)-1\right] \frac{\partial q}{\partial \varepsilon} \\
& =\frac{\beta b}{1-\beta}\left\{u^{\prime}(\hat{q})-1+\left[\pi_{1}\left(\eta_{1}-\varepsilon\right)+\pi_{2}\left(\eta_{2}-\varepsilon\right)\right]\right\} \frac{\partial \hat{q}}{\partial \varepsilon}-\frac{\gamma-\beta}{1-\beta} \frac{\partial \hat{q}}{\partial \varepsilon}
\end{aligned}
$$

Rewrite (15) as follows

$$
\gamma / \beta=b\left[u^{\prime}(q)-1\right]+1+(1-b) i
$$


whereas money holdings by defaulters are determined by

$$
\gamma / \beta=b u^{\prime}(\hat{q})-b+b\left[\pi_{1}\left(\eta_{1}-\varepsilon\right)+\pi_{2}\left(\eta_{2}-\varepsilon\right)\right]+1
$$

Differentiating (38) with respect to $\varepsilon$ yields $(1-b)(\partial i / \partial \varepsilon)=-b u^{\prime \prime}(q)(\partial q / \partial \varepsilon)$. Using (58) and (59) and, (57) becomes

$$
\frac{\partial q}{\partial \varepsilon}=\frac{-\beta b\left(\pi_{1}+\pi_{2}\right) \hat{q} /(1-\beta)}{b u^{\prime \prime}(q) q+[\gamma-1-i(1-b)] /(1-\beta)}
$$

A sufficient condition for the denominator at the right-hand side of $(60)$ to be negative is that $\gamma-1-(1-b) i \leq 0$. From (56), when the borrowing constraint binds $\gamma-1-(1-b) i$ is

$$
\begin{aligned}
& \gamma-1-(1-b) i \\
& =-\beta(1-b) i+\beta b\left[\pi_{1}\left(\eta_{1}-\varepsilon\right)+\pi_{2}\left(\eta_{2}-\varepsilon\right)\right] \hat{q} / q \\
& +\frac{\beta b[u(\hat{q})-u(q)]-(\gamma-\beta+\beta b)(\hat{q}-q)}{q}
\end{aligned}
$$

From Proof of Proposition 4 , when $\varepsilon+(1-b) c<\eta_{2}$ the value of $\gamma$ such that $q=\hat{q}, \hat{\gamma}^{1}$, is $\hat{\gamma}^{1}=1+b \pi_{1}\left(\eta_{2}-\varepsilon\right)+b \pi_{2}\left(\eta_{2}-\varepsilon\right)$. In addition, $q \geq \hat{q}$ and $i \geq$ $b\left[\pi_{1}\left(\eta_{1}-\varepsilon\right)+\pi_{2}\left(\eta_{2}-\varepsilon\right)\right] /(1-b)$ for $\gamma \in\left[\hat{\gamma}^{1}, \hat{\gamma}^{2}\right]$. Therefore, given 61$) \gamma-1-$ $(1-b) i \leq 0$ for $\gamma \in\left[\hat{\gamma}^{1}, \hat{\gamma}^{2}\right]$. Thus, the denominator at the right-hand side of 60 is negative. Since the numerator at the right-hand side of $(60)$ is always negative, it follows that $\partial q / \partial \varepsilon>0$ for $\gamma \in\left[\hat{\gamma}^{1}, \hat{\gamma}^{2}\right]$ and so in a fully constrained equilibrium conversion costs increase agents' lifetime utility. 


\section{References}

V. V. Acharya and S. Steffen. The greatest carry trade ever? understanding eurozone bank risks. Mimeo, March 2013.

M. Aglietta and L. Scialom. The challenge of european integration for prudential policy. Financial Market Group Special Paper, London School of Economics, September 2003.

S. N. Aiyagari and S. Williamson. Money and dynamic credit arrangements with private information. Journal of Economic Theory, 91:248-279, 2000.

A. Alesina and R. J. Barro. Currency unions. Quarterly Journal of Economics, 117: 409-436, 2002.

D. Andolfatto. Essential interest-bearing money. Journal of Economic Theory, 145: 1495-1507, 2010.

T. Beck, editor. Banking Union for Europe: Risks and Challenges. Vox eBook, 2012.

A. Berentsen, G. Camera, and C. Waller. Money, credit and banking. Journal of Economic Theory, 135(1):171-195, 2007.

A. C. Bertay, A. Demirguç-Kunt, and H. Huizinga. Is financial safety net a barrier to cross-border banking? European Bnaking Center Discussion Paper 2011-037, December 2011.

W. Buiter, N. Roubini, R. Repullo, and J. Frankel. Excessive deficits: Sense and nonsense in the Treaty of Maastrich. Economic Policy, 8:57-100, 1993.

V.V. Chari and P.J. Kehoe. On the need for fiscal constraints in a monetary union. Journal of Monetary Economics, 54(8):2399-2408, 2007.

K. Choi and B. Dupont. Revisiting structural change and market integration in late 19th century american capital market. Applied Economics, 39:2733-2741, 2007.

S. Claessens and N. van Horen. Foreign banks: Trends, impact and financial stability. IMF Working Paper, 2012.

L. Clerc, H. Dellas, and O. Loisel. To be or not to be in a monetary union: A synthesis. Journal of International Economics, 83:154-167, 2011. 
B.J. Cohen. The Geography of Money. Cornell University Press, 1998.

R. Cooper and H. Kempf. Commitment and the adoption of a common currency. International Economic Review, 44(1):119-142, 2003.

R. Cooper and H. Kempf. Overturning mundell: fiscal policy in a monetary union. Review of Economic Studies, 71:371-396, 2004.

R. Cooper, H. Kempf, and D. Peled. Is it is or is it ain't my obligation? Regional debt in a fiscal federation. International Economic Review, 49:1469-1504, 2008.

D. Corbae and J. Ritter. Decentralized credit and monetary exchange witwith public record keeping. Economic Theory, 24:933-951, 2004.

L. Davis. The investment market, 1870-1914: The evolution of a national market. Journal of Economic History, 25:355-399, 1965.

P. De Grauwe. Economics of Monetary Union. Oxford University Press, 2007.

ECB. Financial integration in Europe. Technical report, April 2007.

ECB. Financial integration in Europe. Technical report, April 2012.

P. Gomis-Porqueras and D. Sanchez. Optimal monetary policy in a model of money and credit. Journal of Money, Credit and Banking, forthcoming, 2013.

R. Gropp and A. Kashyap. A new metric for banking integration in Europe. NBER Working Paper, 14735, 2009.

D. Gros. The Single European Market in Banking in decline - ECB to the rescue? In T. Beck, editor, Banking Union for Europe. Risks and challenges, pages 51-55. Vox eBook, 2012.

P. Hartmann, A. Maddaloni, and S. Manganelli. The euro area financial system: structure, integration and policy initiatives. Oxford Review of Economic Policy, 19(1):180-213, 2003.

P. He, L. Huang, and R. Wright. Money, banking \& monetary policy. Journal of Monetary Economics, 55:p. 1013-1024, 2008.

E. Helleiner. The Making of National Money: Territorial Currencies in Historical Perspective. Cornell University Press, 2003. 
T. W. Hu, J. Kennan, and N. Wallace. Coalition-proof trade and the Friedman rule in the Lagos-Wright model. Journal of Political Economy, 117:116-137, 2009.

J. A. James. The evolution of the national money market, 1888-1911. The Journal of Economic History, 36:878-897, 1976.

J. A. James and D. F. Weiman. From drafts to checks: The evolution of correspondent banking networks and the formation of the modern U.S. payments system, 1850-1914. Journal of Money, Credit and Banking, 42(2-3):237-265, March - April 2010 .

N. Jentzsch. Do we need a European Directive for credit reporting? In Ifo Institute for Economic Research, editor, CESifo DICE Report, volume 5, pages 48-54, 2007.

N. Jentzsch and A. San José Rientra. Information sharing and its implications for consumer credit markets: United States vs. Europe. mimeo, 2003.

A. Jochem and U. Volz. Portfolio holdings in the euro area - home bias and the role of international, domestic and sector-specific factors. Bundesbank Discussion Paper Economic Studies 07, 2011.

S. Kalemli-Ozcan, E. Papaioannou, and J.-L. Peydr. What lies beneath the euro's effect on financial integration? currency risk, legal harmonization, or trade? Journal of International Economics, 81:75-88, 2010.

N. Kiyotaki and J. Moore. A cost of unified currency. In P. Mizen, editor, Central Banking, Monetary Theory and Practice: Essays in Honour of Charles Goodhart. Edward Elgar Publishing, 2003.

S. Kleimeier and H. Sander. Integrating Europe retail banking markets: Where do we stand? Technical report, Centre for European Policy Studies, 2007.

N. R. Kocherlakota and T. Krueger. A signaling model of multiple monies. Review of Economic Dynamics, 2:231-244, 1999.

Q. Liu and S. Shi. Currency areas and monetary coordination. International Economic Review, 51(3):813-836, 2010.

M. Manna. Home bias in interbank lending and banks' resolution regimes. Bank of Italy working papers "Temi di Discussione' 816, July 2011. 
R. Mundell. A theory of optimum currency areas. American Economic Review, 51: 657-665, 1961.

M. J. Nieto and E. N. White. Will bank supervision in Ohio and Austria be similar? a transatlantic view of the Single Supervisory Mechanism. Column, March, 22 2013. URL http://www . voxeu.org/.

B. Ravikumar and N. Wallace. A benefit of uniform currency? manuscript, Pennsylvania State University, 2001.

G. Rocheteau and R. Wright. Money in search equilibrium, in competitive equilibriu, and in competitive search equilibrium. Econometrica, 73:175-202, 2005.

H. Rockoff. Monetary Unions: Theory, History, Public choice, chapter How Long Did it Take the United States to Become an Optimal Currency Area, pages 70-103. Routledge, 2003.

P. L. Rousseau. Politics on the road to the u.s. monetary union. Vanderbilt University Department of Economics Working Papers 13-00006, 2013.

T. Sargent. United States then, Europe now. Journal of Political Economy, 120: $1-40,2012$.

D. Schoenmaker and T. Bosch. Is the home bias in equities and bonds declining in europe? Investment Management and Financial Innovations, 5:90-102, 2008.

C. L. Sørensen and J. M. P. Gutirrez. Euro area banking sector integration: using hierarchical cluster analysis techniques. ECB Working Papers 627, May 2006.

R. Sylla. Federal policy, banking market structure and capital mobilization in the united states, 1863-1913. The Journal of Economic History, 29(4):657-686, December 1969.

J. Von Hagen and B. Eichengreen. Federalism, fiscal restraints, and European Monetary Union. American Economic Review, 86:134-138, 1996.

D. F. Weiman and J. A. James. The political economy of the u.s. monetary union: The civil war era as a watershed. American Economic Review, 97(2):271-275, May 2007. 
E. N. White. The political economy of banking regulation, 1864-1933. Journal of Economic History, 42:33-40, 1982. 


\section{Documents de Travail}

440. P. A. Pintus and J. Suda, "Learning Leverage Shocks and the Great Recession,” August 2013

441. G. Cette, J. Lopez et J. Mairesse, “Upstream product market regulations, ICT, R\&D and productivity,” August 2013

442. M. Juillard, H. Le Bihan and S. Millard, "Non-uniform wage-staggering: European evidence and monetary policy implications," August 2013

443. G. Cheng, “A Growth Perspective on Foreign Reserve Accumulation,” August 2013

444. D. Wesselbaum, "Procyclical Debt as Automatic Stabilizer," September 2013

445. A. Berthou and V. Vicard, "Firms' Export Dynamics: Experience vs. Size,” September 2013

446. S. Dubecq, A. Monfort, J-P. Renne and G. Roussellet, "Credit and Liquidity in Interbank Rates: a Quadratic Approach," September 2013

447. V. Bignon, R. Esteves and A. Herranz-Loncán, "Big Push or Big Grab? Railways, Government Activism and Export Growth in Latin America, 1865-1913," September 2013

448. C. D’Avino, “Net interoffice accounts of global banks: the role of domestic funding," September 2013

449. J. Dugast, "Limited Attention and News Arrival in Limit Order Markets,” October 2013

450. V. Bignon, R. Breton and M. Rojas Breu, “Currency Union with or without Banking Union,” October 2013

Pour accéder à la liste complète des Documents de Travail publiés par la Banque de France veuillez consulter le site : $\underline{\text { www.banque-france.fr }}$

For a complete list of Working Papers published by the Banque de France, please visit the website: www.banque-france.fr

Pour tous commentaires ou demandes sur les Documents de Travail, contacter la bibliothèque de la Direction Générale des Études et des Relations Internationales à l'adresse suivante :

For any comment or enquiries on the Working Papers, contact the library of the Directorate General Economics and International Relations at the following address :

BANQUE DE FRANCE

49- 1404 Labolog

75049 Paris Cedex 01

tél : 0033 (0)1 42977724 ou 0142926340 ou 4890 ou 6981

email : 1404-ut@banque-france.fr 